\title{
Perturbations in myocardial perfusion and oxygen balance in swine with multiple risk factors: a novel model of ischemia and no obstructive coronary artery disease
}

\author{
Jens van de Wouw ${ }^{1}$. Oana Sorop ${ }^{1} \cdot$ Ruben W. A. van Drie ${ }^{1} \cdot$ Richard W. B. van Duin $^{1} \cdot$ Isabel T. N. Nguyen $^{2}$. \\ Jaap A. Joles ${ }^{2} \cdot$ Marianne C. Verhaar ${ }^{2} \cdot$ Daphne Merkus $^{1,3,4} \cdot$ Dirk J. Duncker $^{1}$
}

Received: 20 November 2018 / Accepted: 14 January 2020 / Published online: 25 February 2020

(c) The Author(s) 2020

\begin{abstract}
Comorbidities of ischemic heart disease, including diabetes mellitus (DM), hypercholesterolemia (HC) and chronic kidney disease (CKD), are associated with coronary microvascular dysfunction (CMD). Increasing evidence suggests that CMD may contribute to myocardial 'Ischemia and No Obstructive Coronary Artery disease' (INOCA). In the present study, we tested the hypothesis that CMD results in perturbations in myocardial perfusion and oxygen delivery using a novel swine model with multiple comorbidities. DM (streptozotocin), HC (high-fat diet) and CKD (renal embolization) were induced in 10 female swine (DM + HC $+\mathrm{CKD})$, while 12 healthy female swine on a normal diet served as controls (Normal). After 5 months, at a time when coronary atherosclerosis was still negligible, myocardial perfusion, metabolism, and function were studied at rest and during treadmill exercise. DM $+\mathrm{HC}+\mathrm{CKD}$ animals showed hyperglycemia, hypercholesterolemia, and impaired kidney function. During exercise, DM + HC + CKD swine demonstrated perturbations in myocardial blood flow and oxygen delivery, necessitating a higher myocardial oxygen extraction—achieved despite reduced capillary density—resulting in lower coronary venous oxygen levels. Moreover, myocardial efficiency was lower, requiring higher oxygen consumption for a given level of myocardial work. These perturbations in myocardial oxygen balance were associated with lower myocardial lactate consumption, stroke volume, and $\mathrm{LVdP} / \mathrm{d} t_{\max }$, suggestive of myocardial ischemia and dysfunction. Further analyses showed a reduction in adenosine-recruitable coronary flow reserve, but this was exclusively the result of an increase in basal coronary blood flow, while maximal coronary flow per gram of myocardium was maintained; the latter was consistent with the unchanged arteriolar wall/lumen ratio, arteriolar density and peri-arteriolar collagen content. However, isolated small arteries displayed selective blunting of endothelium-dependent vasodilation in response to bradykinin in $\mathrm{DM}+\mathrm{HC}+\mathrm{CKD}$ swine, suggesting that changes in coronary microvascular function rather than in structure contributed to the perturbations in myocardial oxygen delivery. In conclusion, common comorbidities in swine result in CMD, in the absence of appreciable atherosclerosis, which is severe enough to produce perturbations in myocardial oxygen balance, particularly during exercise, resembling key features of INOCA.
\end{abstract}

Keywords Diabetes mellitus · Hypercholesterolemia $\cdot$ Chronic kidney disease $\cdot$ Coronary microcirculation $\cdot$ INOCA . Swine $\cdot$ Ischemia $\cdot$ Exercise

Electronic supplementary material The online version of this article (https://doi.org/10.1007/s00395-020-0778-2) contains supplementary material, which is available to authorized users.

Dirk J. Duncker

d.duncker@erasmusmc.nl

Extended author information available on the last page of the article

\section{Introduction}

Common comorbidities of cardiovascular disease, including diabetes mellitus (DM), hypercholesterolemia (HC) and chronic kidney disease (CKD), are well-known risk factors for the development of coronary artery disease of both large epicardial arteries and smaller coronary arteries $[8,13,18,31]$. While it is well established that obstructive coronary artery disease (CAD) is a major cause of myocardial ischemia [19], there is increasing evidence that 
coronary microvascular dysfunction (CMD) also contributes to myocardial ischemia, not only in the presence of obstructive CAD [1, 14, 36, 55] but also in patients without obstructive CAD, a situation referred to as 'Ischemia and No Obstructive Coronary Artery disease' (INOCA) [2, 8, $36,44]$. Clinical studies have shown that INOCA is present in approximately one-third of men and two-thirds of women undergoing angiography for suspected ischemic heart disease and that cardiovascular death or myocardial infarction occurred in $6.7 \%$ of the patients without any signs of CAD and in $12.8 \%$ of patients with non-obstructive CAD [32, 53].

Although the mechanisms underlying INOCA remain incompletely understood, there is increasing evidence that CMD, in particular impaired endothelium-dependent vasodilation, plays an important role $[2,10,13,66]$. In agreement with these clinical observations, experimental data obtained in swine chronically exposed to multiple comorbidities, also demonstrate endothelial dysfunction of isolated small coronary arteries studied in vitro, in the absence of obstructive CAD [54, 57, 63]. However, whether these perturbations in coronary microvascular endothelial function translate into impaired myocardial perfusion and oxygen delivery in vivo, i.e., result in INOCA, was not assessed in these studies. Consequently, we tested the hypothesis that combined comorbidities — as frequently present in patients—result in perturbations in myocardial perfusion and oxygen delivery, causing a shift towards anaerobic metabolism and cardiac dysfunction, particularly during increased myocardial oxygen demand. To test our hypothesis, we studied swine that were chronically (5 months) exposed to a combination of three common comorbidities-DM + HC + CKD-and that have been extensively phenotyped in our previous study [54]. Here, swine were chronically instrumented after 5-months of exposure to $\mathrm{DM}+\mathrm{HC}+\mathrm{CKD}$, to allow the assessment of systemic and coronary hemodynamics as well as myocardial metabolism and function in the awake state, at rest and during treadmill exercise.

\section{Materials and methods}

\section{Animals}

All animal experiments were approved by the Animal Care Committee at the Erasmus University Medical Center (Rotterdam, The Netherlands) and performed in accordance with the "Guiding Principles in the Care and Use of Laboratory Animals" as approved by the Council of the American Physiological Society. Ten female Yorkshire $\times$ Landrace swine $(25 \pm 1 \mathrm{~kg})$ were included in the $\mathrm{DM}+\mathrm{HC}+\mathrm{CKD}$ group while 12 healthy female Yorkshire $\times$ Landrace swine of similar age and weight were used as controls (Normal). Two swine assigned to the $\mathrm{DM}+\mathrm{HC}+\mathrm{CKD}$ group died prematurely, one animal died 2 weeks after CKD induction and one animal died during chronic instrumentation due to surgical complications. In the Normal group, also two swine were lost. One animal died during chronic instrumentation, while another animal experienced severe lameness prior to chronic instrumentation and was excluded from the study. Four additional swine (two Normal and two $\mathrm{DM}+\mathrm{HC}+\mathrm{CKD}$ ) were included for measuring coronary flow reserve (CFR) in vivo and small artery function ex vivo. An overview of the experimental design and technical procedures is presented in Fig. 1.

\section{Induction of comorbidities}

The induction of comorbidities in the $\mathrm{DM}+\mathrm{HC}+\mathrm{CKD}$ group has been described in detail elsewhere [54]. Briefly, DM was induced by injecting streptozotocin (Bio-Connect B.V., Huissen, The Netherlands) at a dose of $50 \mathrm{mg} \mathrm{kg}^{-1}$ day $^{-1}$ i.v. for 3 consecutive days. The severity and stability of DM was monitored bi-weekly by measuring blood glucose and ketone levels.

Two weeks after DM induction, animals were sedated with intramuscular injection of a cocktail of Zoletil (tiletamine/zolazepam; $5 \mathrm{mg} \mathrm{kg}^{-1}$ ), Sedazine (xylazine; $2.25 \mathrm{mg} \mathrm{kg}^{-1}$ ) and atropine ( $2 \mathrm{mg}$ ) and artificially ventilated $\left(\mathrm{O}_{2}\right.$ and $\mathrm{N}_{2}[1: 2 \mathrm{vol} / \mathrm{vol}]$, to which $1-2 \%$ ( $\mathrm{vol} / \mathrm{vol}$ ) isoflurane was added for anesthesia). CKD was produced by microembolization of the global right kidney as well as the lower pole of the left kidney. For this purpose, the renal arteries were catheterized under fluoroscopy guidance (right renal artery and selective catheterization of the artery perfusing the left lower renal pole) with a Swan-Ganz catheter, inserted through a 9F sheath in the right common carotid artery. Following inflation of the balloon to prevent backflow into the aorta, $75 \mathrm{mg}$ of polyethylene microspheres with a diameter of 38-42 $\mu \mathrm{m}$ (Cospheric, Santa Barbara, CA, USA) were infused into each kidney via the distal port of the catheter. The wound was closed and the animals were allowed to recover.

One week after CKD induction, a high-fat and high-sugar diet containing 10\% sucrose, $15 \%$ fructose, $25 \%$ saturated fats and 1\% cholesterol (Research Diets Services BV, Wijk bij Duurstede, The Netherlands) supplemented with sodium chloride $\left(20 \mathrm{~g} \mathrm{day}^{-1}\right)$ was gradually introduced. The Normal group continued to receive regular swine chow. Animals were housed in pairs but were fed separately and had ad libitum access to drinking water.

\section{Chronic instrumentation}

After an overnight fast, Normal and DM $+\mathrm{HC}+\mathrm{CKD}$ swine (5 months after CKD induction) were sedated with an intramuscular injection of a cocktail of Zoletil 


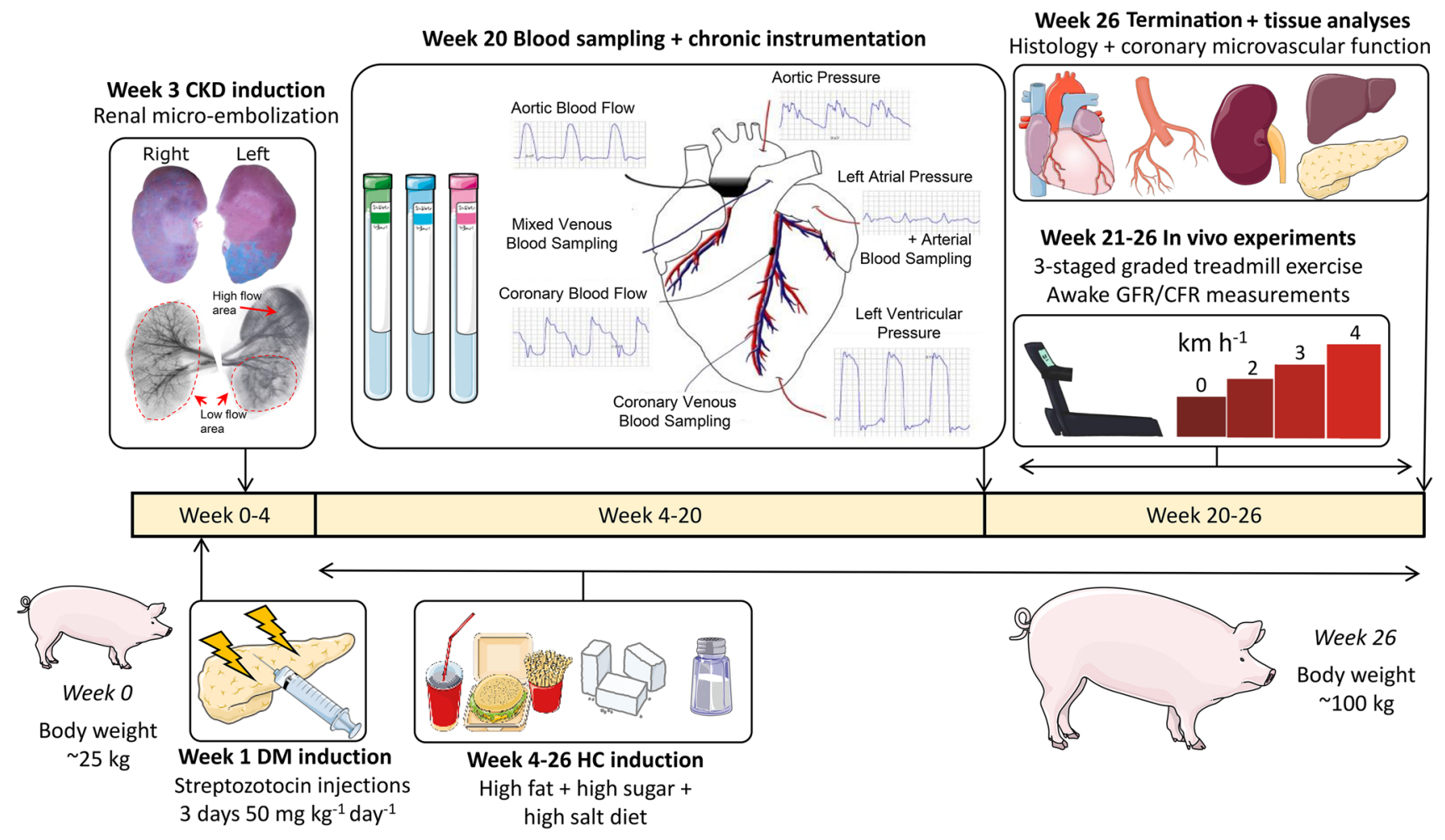

Fig. 1 Experimental timeline of the $\mathrm{DM}+\mathrm{HC}+\mathrm{CKD}$ swine from induction of the comorbidities to the termination. High-fat + highsugar +high-salt diet was composed of $10 \%$ sucrose, $15 \%$ fructose, $25 \%$ saturated fats, and $1 \%$ cholesterol supplemented with sodium chloride $\left(20 \mathrm{~g} \mathrm{day}^{-1}\right)$. Normal swine were weight- and age-matched to the $\mathrm{DM}+\mathrm{HC}+\mathrm{CKD}$ swine, were fed normal chow without receiv-

(tiletamine/zolazepam; $5 \mathrm{mg} \mathrm{kg}^{-1}$ ), Sedazine (xylazine; $\left.2.25 \mathrm{mg} \mathrm{kg}^{-1}\right)$ and atropine $(2 \mathrm{mg})$, and artificially ventilated $\left(\mathrm{O}_{2}\right.$ and $\mathrm{N}_{2}$ [1:2; vol/vol]), to which $2-2.5 \%$ (vol/vol) isoflurane was added. As described in detail elsewhere [15], a thoracotomy was performed in the fourth left intercostal space under sterile conditions and fluid-filled polyvinylchloride catheters were placed in the left ventricle, aorta, pulmonary artery, and left atrium for pressure measurements and blood sampling. Additionally, flow probes (Transonic Systems, Ithaca, NY) were placed around the aorta for cardiac output measurement, and around the proximal left anterior descending coronary artery to measure coronary blood flow. Finally, two small angio-catheters (one as backup) were inserted into the anterior inter-ventricular vein for coronary venous blood sampling. In one Normal and in one $\mathrm{DM}+\mathrm{HC}+\mathrm{CKD}$ animal, the coronary venous angiocatheters lost patency prior to the exercise study. Electrical wires and catheters were tunneled subcutaneously to exit through the back of the animal and protected with a vest. Then the chest was closed and animals were allowed to recover, receiving analgesia ( $0.3 \mathrm{mg}$ buprenorphine i.m.) and a slow-release fentanyl patch $\left(50 \mu \mathrm{g} \mathrm{h}^{-1}\right)$ for 6 days, ing the induction of any comorbidities, and underwent chronic instrumentation, in vivo experiments and termination according to a similar protocol as $\mathrm{DM}+\mathrm{HC}+\mathrm{CKD}$ swine. $D M$ diabetes mellitus, $C K D$ chronic kidney disease, $H C$ hypercholesterolemia, $G F R$ glomerular filtration rate, $C F R$ coronary flow reserve

and antibiotic prophylaxis (25 $\mathrm{mg} \mathrm{kg}^{-1}$ amoxicillin i.v.) for 7 days. All catheters were flushed daily with heparinized saline (1000-5000 $\mathrm{IU} \mathrm{ml}^{-1}$ saline) to prevent the formation of blood clots and maintain catheter patency. One $\mathrm{DM}+\mathrm{HC}+\mathrm{CKD}$ swine had a malfunctioning coronary flow probe.

\section{In vivo experiments in awake swine}

Experiments started 1 week after surgery. First, the glomerular filtration rate (GFR) was measured at rest, using continuous inulin infusion [54]. On a subsequent day, myocardial perfusion and function at rest and during exercise were assessed using a motor-driven treadmill exercise protocol. Briefly, resting hemodynamic measurements, blood samples, and rectal temperature were obtained with swine standing quietly on the treadmill. Then swine were subjected to a three-stage incremental treadmill exercise protocol (2, 3 and $4 \mathrm{~km} \mathrm{~h}^{-1}$ at $0 \%$ inclination, 3 min per stage). Hemodynamic variables were continuously recorded digitally on a Codas workstation (ATCODAS, Dataq Instruments, Akron, $\mathrm{OH}$ ), with blood samples collected during the final $30 \mathrm{~s}$ of each 
exercise stage when steady-state hemodynamics had been achieved. Blood samples were analyzed for $p \mathrm{O}_{2}, p \mathrm{CO}_{2}, \mathrm{pH}$, bicarbonate, $\mathrm{O}_{2}$ saturation $\left(\mathrm{SaO}_{2}\right)$, lactate and hemoglobin concentration (ABL-800, Radiometer, Copenhagen).

In a seperate experiment, coronary blood flow was measured in awake resting swine (4 Normal and 4 $\mathrm{DM}+\mathrm{HC}+\mathrm{CKD}$ ) under basal conditions and during maximal coronary vasodilation using intravenous infusion of adenosine $\left(0.5 \mathrm{mg} \mathrm{kg}^{-1} \mathrm{~min}^{-1}\right)$ in combination with phenylephrine $\left(5-7.5 \mu \mathrm{g} \mathrm{kg}^{-1} \mathrm{~min}^{-1}\right)$ to maintain mean arterial pressure at baseline levels [55]. CFR was calculated as maximal coronary blood flow divided by basal coronary blood flow.

\section{Termination}

At the termination, swine were sedated by intramuscular injection with a cocktail of Zoletil (tiletamine/zolazepam; $5 \mathrm{mg} \mathrm{kg}^{-1}$ ), Sedazine (xylazine; $2.25 \mathrm{mg} \mathrm{kg}^{-1}$ ) and atropine $(2 \mathrm{mg})$ and anesthetized with pentobarbital $\left(9 \mathrm{mg} \mathrm{kg}^{-1} \mathrm{~h}^{-1}\right.$ i.v.). Subsequently, a sternotomy was performed and ventricular fibrillation was induced using a $9 \mathrm{~V}$ battery, and immediately the heart, kidneys, liver and pancreas were excised, weighed, prepared, and stored for later biochemical, molecular, and histological analyses.

\section{In vitro coronary small artery function}

In a subgroup of animals ( $3 \mathrm{Normal}$ and $3 \mathrm{DM}+\mathrm{HC}+\mathrm{CKD}$ ), coronary small arteries ( $~ 300 \mu \mathrm{m}$ diameter) were isolated from the epicardial surface of the left ventricular apex and studied in vitro using a Mulvany wire myograph (DMT, Aarhus, Denmark). Vasodilation to the endotheliumdependent vasodilator bradykinin (BK, $3 \times 10^{-9}, 10^{-8}$ and $3 \times 10^{-8} \mathrm{~mol} \mathrm{~L}^{-1}$, Sigma-Aldrich, Zwijndrecht, The Netherlands) and the nitric oxide donor and endotheliumindependent vasodilator S-nitroso- $\mathrm{N}$-acetylpenicillamine (SNAP, $10^{-7}, 3 \times 10^{-7}$ and $10^{-6} \mathrm{~mol} \mathrm{~L}^{-1}$, Sigma-Aldrich) were measured following preconstriction with $10^{-6} \mathrm{~mol} \mathrm{~L}^{-1}$ of the thromboxane-A2 analogue U46619 (Sigma-Aldrich).

\section{Plasma and tissue analyses}

Fasting arterial blood samples were obtained at instrumentation and stored at $-80^{\circ} \mathrm{C}$, for later determination of plasma glucose, triglycerides, total cholesterol, low-density lipoprotein (LDL), high-density lipoprotein (HDL), aspartate aminotransferase (ASAT), alanine aminotransferase (ALAT), albumin, sodium, and creatinine, as previously described [54]. Arterial plasma concentrations of tumor necrosis factor alpha (TNF- $\alpha$, R\&D Systems Europe Ltd., Abingdon, UK), neutrophil gelatinase-associated lipocalin (Pig NGAL, BioPorto Diagnostics A/S, Hellerup, Denmark), and fasting insulin (Porcine Insulin, Mercodia AB, Uppsala, Sweden) were determined using ELISA kits.

Samples of the pancreas, liver, kidney, left anterior descending artery, right coronary artery, left circumflex artery, and left ventricular anterior free wall were excised, cryo-embedded in Tissue-Tek or fixed in $4 \%$ buffered formaldehyde, and embedded in paraffin for histological analyses. 4.5- $\mu \mathrm{m}$-thick slides of the pancreas were stained for insulin (FLEX polyclonal anti-insulin, Agilent Technologies, Santa Clara, CA). Six to eight fields at $200 \times$ magnification were analyzed and data were averaged per animal. Cryosections of the liver ( $4 \mu \mathrm{m}$ thick) were stained with Oil Red O (Sigma-Aldrich) for quantification of liver fat deposition. Five to seven liver lobes were analyzed and data were averaged per animal.

From formaldehyde-fixed, paraffin-embedded kidneys, $3-\mu \mathrm{m}$ sections were sliced and stained. For the analysis, the upper pole of the left kidney, which was not embolized, was used. Tubulo-interstitial damage and glomerulosclerosis were scored on periodic acid-Schiff-stained sections in a blinded manner. The tubulo-interstitial damage was scored in at least 20 different non-overlapping fields per animal at a magnification of $200 \times$. The amount of inflammatory infiltrate between tubuli, interstitial fibrosis, tubular atrophy, and dilatation were scored on a scale of $0-5$, with 0 indicating not present, and 5 indicating that $>75 \%$ of all tubuli were affected. A total tubulo-interstitial damage score was calculated by summing the scores for the four variables. Glomerular score was performed at a magnification of $400 \times$ on 50 separate glomeruli. The analysis was done by quadrants, with the score of 0 indicating that no quadrant was affected and 4 indicating that the whole glomerulus was affected. Scored variables were matrix expansion, sclerosis, adhesion of Bowman's capsule and dilation, from which a total glomerulosclerosis score was then calculated. All renal histological analyses were performed by observers blinded to the treatment of the animal.

Left ventricular anterior wall sections $(4.5 \mu \mathrm{m}$ thick) were stained for the quantification of myocardial collagen deposition, myocyte size, and capillary density. Six to eight fields were examined in the endocardial part of each slide, at $200 \times$ magnification. Collagen deposition was assessed using Picrosirius red staining, with interstitial and perivascular collagen deposition being analyzed separately. Using light microscopy, interstitial collagen was measured as area occupied by all collagen fibers and expressed as a percentage of the myocardial area, perivascular collagen being excluded from this analysis. Using a linear polarization filter, the percentage area of the myocardium occupied specifically by collagen type I and III fibers was measured [64]. Perivascular collagen deposition was measured for all coronary arterioles (diameter $<100 \mu \mathrm{m}$, excluding capillaries) encountered in the left ventricular section at $200 \times$ magnification 
$\left(\sim 150 \mathrm{~mm}^{2}\right)$ and expressed as ratio between the perivascular area and the lumen diameter. The latter was defined as the area encompassed by two times the distance from the lumen center to the external elastic lamina in all directions. Crosssectional areas of cardiomyocytes with clearly visible nuclei were measured for each slide, using a Gomori silver stain. Capillary density was quantified using an endothelial cells staining with biotin-labeled lectin (lectin $1 / 100$ in $1 \%$ bovine serum albumin in PBS, Sigma-Aldrich). All vessels smaller than $10 \mu \mathrm{m}$ in diameter and without vascular smooth muscle cells were counted. Capillary to fiber ratio was calculated by dividing capillary density by the total number of cardiomyocytes per $\mathrm{mm}^{2}$.

Right coronary artery, left circumflex artery, left anterior descending artery, and left ventricular sections were stained with resorcin-fuchsin solution to assess media-to-lumen ratios of large coronary arteries and coronary arterioles ( $<100 \mu \mathrm{m}$ inner diameter, excluding capillaries). Smooth muscle actin was stained (EnVision Gl2 doublestain rabbit/ mouse, Agilent Technologies, Santa Clara, CA, USA) in left ventricular sections to determine coronary arteriolar densities, according to an earlier described protocol [65]; in short, we counted arterioles of $<100 \mu \mathrm{m}$ inner diameter with $>2$ smooth muscle layers. All measurements, except for renal histological measurements, were performed using a microscopy image analysis system (Impak C, Clemex Vision Image analysis system, Clemex Technologies, Quebec, Canada).

\section{Data analysis and statistics}

Data are presented as mean \pm SEM. Digital recording and offline analysis of hemodynamic data obtained at rest and during exercise was performed. Body $\mathrm{O}_{2}$ consumption $\left(\mathrm{B} V \mathrm{O}_{2}\right)$ was calculated as the product of cardiac output and the difference in $\mathrm{O}_{2}$ content between arterial and mixed venous blood. Systemic vascular conductance (SVC) was computed as the ratio of cardiac output and mean arterial pressure. Myocardial $\mathrm{O}_{2}$ and lactate delivery were computed as the product of coronary blood flow and arterial blood $\mathrm{O}_{2}$ content or arterial lactate concentration. Myocardial $\mathrm{O}_{2}$ $\left(\mathrm{MVO}_{2}\right)$ and lactate consumption were calculated as the product of coronary blood flow and the difference in $\mathrm{O}_{2}$ content or lactate concentration between arterial and coronary venous blood. Myocardial oxygen extraction was computed as $100 \% \mathrm{MVO}_{2} /$ Myocardial $\mathrm{O}_{2}$ delivery. Myocardial work was computed as the product of cardiac output and systolic arterial pressure. Systemic parameters, including cardiac output, $\mathrm{B} V \mathrm{O}_{2}$, SVC, cardiac work, and stroke volume, were normalized for body weight in kilograms $(\mathrm{kg})$. Myocardial parameters including $\mathrm{MVO}_{2}$, coronary blood flow, myocardial oxygen and lactate delivery, and myocardial lactate consumption were normalized per gram (g) of myocardium perfused by the left anterior descending coronary artery, which was estimated to be $40 \%$ of the left ventricle $[9,30]$.

Statistical analysis was performed in SPSS Statistics 21.0 (IBM Corp, Armonk, NY). Two-way ANOVA for repeated measures was used to analyze tabular in vivo hemodynamic and myocardial oxygen balance responses to graded treadmill exercise, as well as the ex vivo microvascular function, with Bonferroni post hoc testing when appropriate. A twoway ANCOVA was used to analyze hemodynamic and myocardial oxygen balance data expressed as a function of whole body — or myocardial-oxygen consumption. Comparison of other variables between the two groups was performed by unpaired Student's $t$ test. Correlations were calculated by Pearson's correlation. Statistical significance was accepted when $p<0.05$ (two tailed).

\section{Results}

\section{Model characteristics}

Metabolic, renal, inflammatory, and cardiac characteristics of the $\mathrm{DM}+\mathrm{HC}+\mathrm{CKD}$ swine model at 5-month follow-up are presented in Table 1, while representative histological sections of pancreas, liver, kidney, left anterior descending coronary artery and left ventricular anterior wall are shown in Fig. 2. Metabolic dysfunction was present in $\mathrm{DM}+\mathrm{HC}+\mathrm{CKD}$ swine, with markedly elevated levels of plasma glucose, total cholesterol and LDL/HDL ratio, and similar triglyceride levels $(p=0.10)$ as compared to healthy Normal swine. Pancreas staining demonstrated an $\sim 80 \%$ reduction of the insulin-producing $\beta$-cells in the islets of Langerhans in DM + HC + CKD swine, but insulin plasma levels were maintained. There was no difference in ASAT plasma levels between groups, while ALAT levels even decreased in $\mathrm{DM}+\mathrm{HC}+\mathrm{CKD}$ compared to Normal swine. In addition, $\mathrm{DM}+\mathrm{HC}+\mathrm{CKD}$ showed a trend towards an increase in liver fat deposition $(p=0.09)$, which correlated positively with plasma levels of total cholesterol $\left(r^{2}=0.519, p<0.05\right)$ and correlated inversely with ASAT $\left(r^{2}=0.466, p<0.05\right)$. Although kidney weights were not different from Normal swine, renal dysfunction was present in $\mathrm{DM}+\mathrm{HC}+\mathrm{CKD}$ swine reflected in increased creatinine plasma levels and a significantly impaired GFR, as measured by inulin clearance, increased histological scores of tubulointerstitial injury, and glomerular sclerosis. Metabolic and renal dysfunction resulted in elevated TNF- $\alpha$ plasma levels. Absolute and relative left ventricular weights were not different between groups. Similarly, cardiomyocyte crosssectional area showed no significant differences between groups. In contrast, total collagen deposition (collagen type I and III) was elevated in $\mathrm{DM}+\mathrm{HC}+\mathrm{CKD}$ compared to Normal swine. Interestingly, this elevation was due to 
Table 1 Metabolic, renal, inflammatory and myocardial characteristics of Normal and $\mathrm{DM}+\mathrm{HC}+\mathrm{CKD}$ swine

\begin{tabular}{|c|c|c|c|c|}
\hline & $n^{\mathrm{a}}$ & $n^{\mathrm{b}}$ & Normal & $\mathrm{DM}+\mathrm{HC}+\mathrm{CKD}$ \\
\hline Body weight (kg) & 10 & 9 & $93 \pm 6$ & $104 \pm 6$ \\
\hline \multicolumn{5}{|l|}{ Metabolic function } \\
\hline Plasma fasting glucose $\left(\mathrm{mmol} \mathrm{L}^{-1}\right)$ & 10 & 9 & $8.4 \pm 0.8$ & $19.2 \pm 1.5^{*}$ \\
\hline Plasma insulin $\left(\mu \mathrm{g} \mathrm{L}^{-1}\right)$ & 9 & 9 & $0.08 \pm 0.03$ & $0.26 \pm 0.16$ \\
\hline HOMA-IR & 8 & 9 & $1.13 \pm 0.60$ & $7.36 \pm 4.61$ \\
\hline$\beta$-Cells of islets of Langerhans (\%) & 6 & 7 & $100 \pm 12$ & $17 \pm 4^{*}$ \\
\hline Plasma total cholesterol $\left(\mathrm{mmol} \mathrm{L}^{-1}\right)$ & 10 & 9 & $1.72 \pm 0.08$ & $8.28 \pm 0.86^{*}$ \\
\hline LDL/HDL cholesterol ratio & 10 & 9 & $1.19 \pm 0.08$ & $3.51 \pm 0.57 *$ \\
\hline Plasma triglycerides $\left(\mathrm{mmol} \mathrm{L}^{-1}\right)$ & 10 & 9 & $0.20 \pm 0.03$ & $0.29 \pm 0.05$ \\
\hline Plasma ALAT $\left(\mathrm{U} \mathrm{L}^{-1}\right)$ & 10 & 9 & $52 \pm 4$ & $24 \pm 4^{*}$ \\
\hline Plasma ASAT (U L L $\left.{ }^{-1}\right)$ & 10 & 9 & $32 \pm 7$ & $23 \pm 3$ \\
\hline Liver steatosis $(\%)$ & 6 & 7 & $0.04 \pm 0.02$ & $1.41 \pm 0.80$ \\
\hline \multicolumn{5}{|l|}{ Renal function and structure } \\
\hline Plasma creatinine $\left(\mu \mathrm{mol} \mathrm{L}{ }^{-1}\right)$ & 10 & 9 & $122 \pm 4$ & $170 \pm 11^{*}$ \\
\hline Glomerular filtration rate $\left(\mathrm{ml} \mathrm{min}^{-1}\right)^{\mathrm{c}}$ & 7 & 7 & $197 \pm 10$ & $132 \pm 14^{*}$ \\
\hline Plasma sodium $\left(\mathrm{mmol} \mathrm{L}^{-1}\right)$ & 10 & 9 & $141 \pm 1$ & $134 \pm 1^{*}$ \\
\hline Plasma albumin $\left(\mathrm{g} \mathrm{L}^{-1}\right)$ & 10 & 9 & $40 \pm 1$ & $31 \pm 2 *$ \\
\hline Plasma NGAL (ng ml ${ }^{-1}$ ) & 6 & 9 & $128 \pm 16$ & $164 \pm 16$ \\
\hline Right kidney weight (g) & 10 & 9 & $200 \pm 14$ & $184 \pm 20$ \\
\hline Left kidney weight (g) & 10 & 9 & $207 \pm 11$ & $177 \pm 22$ \\
\hline Right kidney weight/BW $\left(\mathrm{g} \mathrm{kg}^{-1}\right)$ & 10 & 9 & $1.96 \pm 0.15$ & $1.80 \pm 0.13$ \\
\hline Left kidney weight/BW ( $\mathrm{g} \mathrm{kg}^{-1}$ ) & 10 & 9 & $2.06 \pm 0.13$ & $1.75 \pm 0.14$ \\
\hline Tubulo-interstitial injury score & 6 & 5 & $2.1 \pm 0.4$ & $4.3 \pm 0.6^{*}$ \\
\hline Glomerular sclerosis score & 6 & 5 & $18.2 \pm 3.0$ & $32.4 \pm 3.7^{*}$ \\
\hline \multicolumn{5}{|l|}{ Inflammation } \\
\hline TNF- $\alpha\left(\mathrm{pg} \mathrm{ml}^{-1}\right)$ & 8 & 9 & $25 \pm 5$ & $52 \pm 5^{*}$ \\
\hline \multicolumn{5}{|l|}{ Cardiac structure } \\
\hline Left ventricular weight (g) & 10 & 9 & $277 \pm 12$ & $251 \pm 16$ \\
\hline Left ventricular weight/BW $\left(\mathrm{g} \mathrm{kg}^{-1}\right)$ & 10 & 9 & $2.9 \pm 0.2$ & $2.4 \pm 0.2$ \\
\hline Cardiomyocyte CSA $\left(\mu \mathrm{m}^{2}\right)$ & 10 & 7 & $582 \pm 44$ & $663 \pm 110$ \\
\hline Capillary density $\left(\# \mathrm{~mm}^{-2}\right)$ & 10 & 7 & $1921 \pm 157$ & $1381 \pm 172 *$ \\
\hline Capillary to fiber ratio & 10 & 7 & $1.33 \pm 0.17$ & $0.84 \pm 0.09 *$ \\
\hline Total collagen ( $\%$ of myocardium) & 10 & 7 & $5.7 \pm 0.7$ & $9.6 \pm 1.9^{*}$ \\
\hline \multicolumn{5}{|l|}{ Large coronary structure } \\
\hline LAD media-to-lumen ratio & 10 & 7 & $0.55 \pm 0.05$ & $0.63 \pm 0.11$ \\
\hline LCX media-to-lumen ratio & 7 & 6 & $0.70 \pm 0.09$ & $0.57 \pm 0.10$ \\
\hline RCA media-to-lumen ratio & 9 & 7 & $0.72 \pm 0.10$ & $0.78 \pm 0.10$ \\
\hline
\end{tabular}

Data are mean \pm SEM

$* p<0.05$ Normal vs $\mathrm{DM}+\mathrm{HC}+\mathrm{CKD}$

${ }^{\mathrm{a}} n$ number of animals analyzed in the Normal group

${ }^{\mathrm{b}} n$ number of animals analyzed in the DM $+\mathrm{HC}+\mathrm{CKD}$ group

${ }^{c}$ GFR obtained in awake animals, 1 week after surgery. Plasma samples were obtained under anesthetized basal conditions after onset of surgery

HOMA-IR homeostatic model assessment-insulin resistance, $L D L$ low-density lipoprotein, $H D L$ highdensity lipoprotein, $A L A T$ alanine aminotransferase, ASAT aspartate aminotransferase, $N G A L$ neutrophil gelatinase-associated lipocalin, $B W$ body weight, $T N F-\alpha$ tumor necrosis factor alpha, $C S A$ cross-sectional area, $L A D$ left anterior descending artery, $L C X$ left circumflex artery, $R C A$ right coronary artery increased deposition of collagen type I fibers, known to form thick and stiff bundles, in DM + HC + CKD compared to Normal, while deposition of the compliant thin collagen fibers (collagen type III) was unaltered (Supplemental Figure). Furthermore, significant decreases in left ventricular subendocardial capillary density as well as capillary-to-fiber 

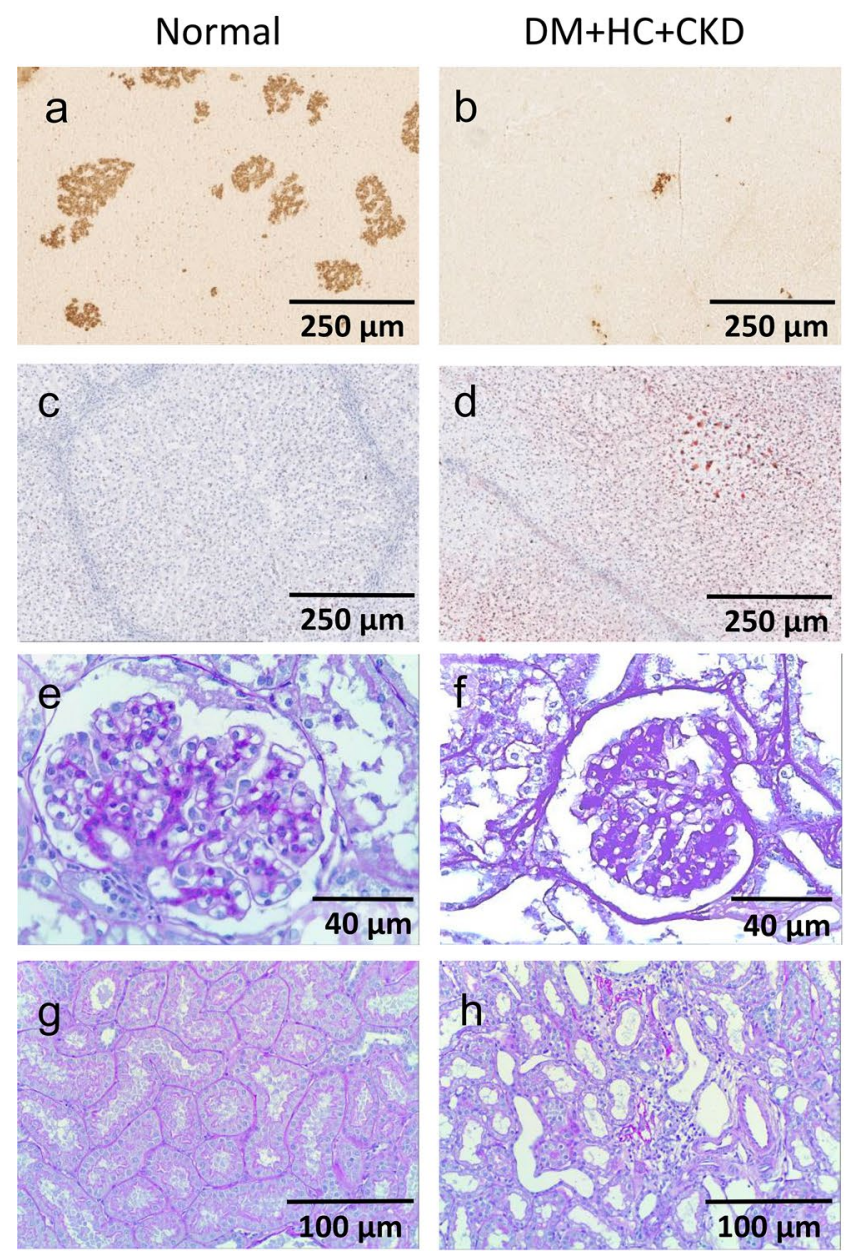

Fig. 2 Representative histological sections of pancreas, liver, kidney, coronary artery, and left ventricle of Normal and DM + HC + CKD swine. Representative insulin-stained pancreas sections $(\mathbf{a}, \mathbf{b})$ and Oil Red O-stained liver sections (c, d) at $\times 100$ magnification, scale bar $=250 \mu \mathrm{m}$. Periodic acid-Schiff-stained sections of a glomerulus $(\mathbf{e}, \mathbf{f})$ at $\times 400$ magnification, scale bar $=40 \mu \mathrm{m}$ and tubuli $(\mathrm{g}$,

ratios were observed in $\mathrm{DM}+\mathrm{HC}+\mathrm{CKD}$ swine. Macroscopic and microscopic examination of the large coronary arteries, showed no signs of atherosclerosis and no changes in media-to-lumen ratio in $\mathrm{DM}+\mathrm{HC}+\mathrm{CKD}$ swine.

\section{Systemic hemodynamics and metabolism}

The impact of comorbidities on systemic hemodynamics and metabolism was assessed at rest and during graded treadmill exercise (Table 2). Although heart rates were similar at rest, the exercise-induced increase in heart rate was blunted in DM + HC + CKD compared to Normal swine, suggestive of chronotropic incompetence. Stroke volume was lower in $\mathrm{DM}+\mathrm{HC}+\mathrm{CKD}$ swine at rest (Table 2). These alterations in cardiac function resulted in a lower cardiac output in $\mathrm{DM}+\mathrm{HC}+\mathrm{CKD}$ compared to
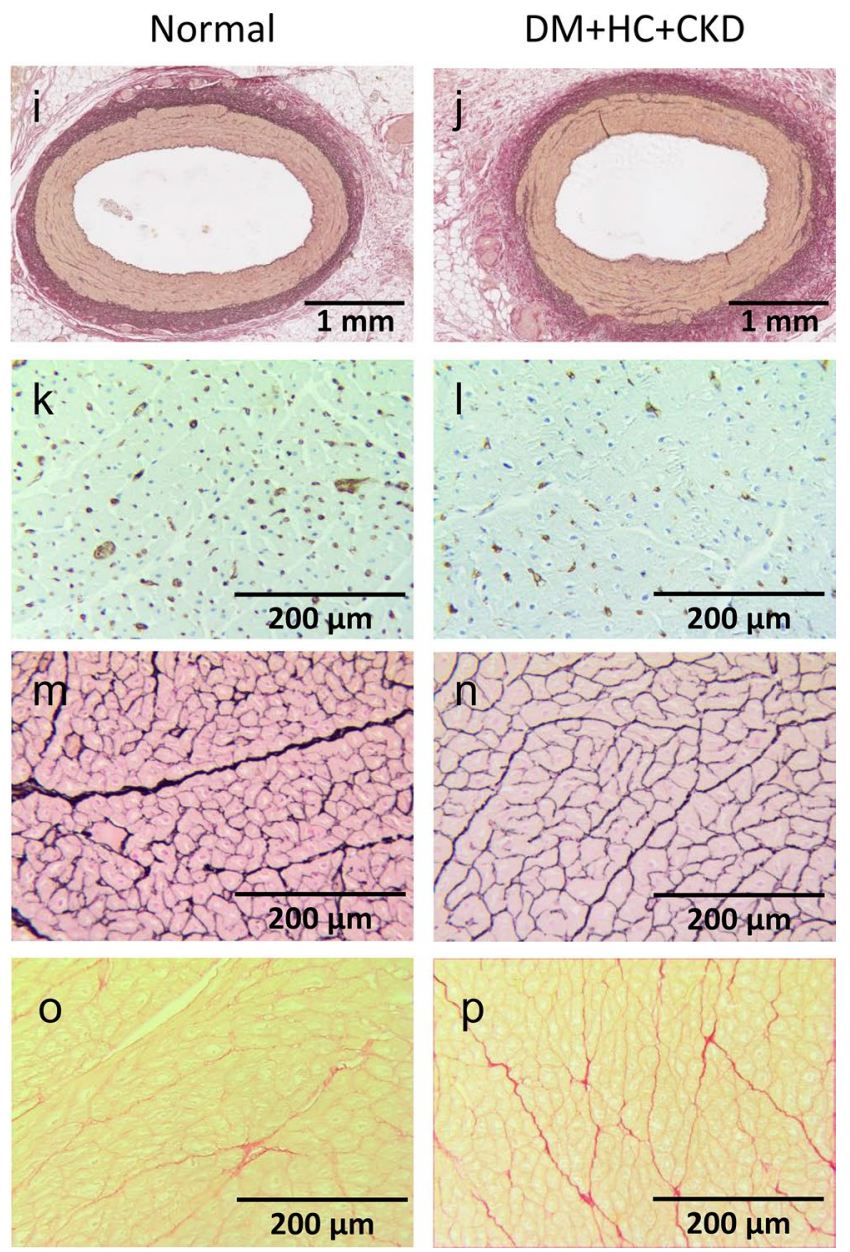

h) from the top part of the left kidney at $\times 200$ magnification, scale bar $=100 \mu \mathrm{m}$. Representative resorcin-fuchsin-stained sections of the left anterior descending artery $(\mathbf{i}, \mathbf{j})$ at $\times 50$ magnification, scale bar $=1 \mathrm{~mm}$. Representative sections of the endocardium of the left ventricle, lectin stained $(\mathbf{k}, \mathbf{l})$, Gomori stained $(\mathbf{m}, \mathbf{n})$ and picrosirius red stained $(\mathbf{o}, \mathbf{p})$ at $\times 200$ magnification, scale bar $=200 \mu \mathrm{m}$

Normal both at rest and during exercise (Table 2, Fig. 3a). Although renal embolization resulted in an acute increase in blood pressure, which we previously showed to be sustained for at least 2 months [54], hypertension was no longer present at 5 months after renal embolization. The normalization of mean aortic blood pressure was likely the result of the reduction in cardiac output, as systemic vascular conductance was still lower in $\mathrm{DM}+\mathrm{HC}+\mathrm{CKD}$ swine (Fig. 3b). The lower cardiac output during exercise was only partly compensated for by an increase in body oxygen extraction (Fig. 3c). Consequently, the exerciseinduced increase in $\mathrm{BVO} \mathrm{O}_{2}$ was blunted in $\mathrm{DM}+\mathrm{HC}+\mathrm{CKD}$ animals, which was associated with increased circulating levels of lactate (Fig. 3d), suggestive of systemic anaerobic metabolism and exercise intolerance. Both arterial $\mathrm{pCO}_{2}$ and bicarbonate levels (arterial $\mathrm{HCO}_{3}{ }^{-}$at rest 
Table 2 Systemic hemodynamics and metabolism of Normal and $\mathrm{DM}+\mathrm{HC}+\mathrm{CKD}$ swine at rest and during treadmill exercise

\begin{tabular}{|c|c|c|c|c|c|}
\hline & \multirow[b]{2}{*}{$n$} & \multirow[t]{2}{*}{ Rest } & \multicolumn{3}{|l|}{ Exercise $\left(\mathrm{km} \mathrm{h}^{-1}\right)$} \\
\hline & & & 2 & 3 & 4 \\
\hline \multicolumn{6}{|c|}{ Heart rate (beats $\min ^{-1}$ ) } \\
\hline Normal & 10 & $122 \pm 3$ & $184 \pm 11^{*}$ & $184 \pm 10^{*}$ & $232 \pm 8^{*}$ \\
\hline $\mathrm{DM}+\mathrm{HC}+\mathrm{CKD}$ & 8 & $117 \pm 4$ & $164 \pm 9 *$ & $177 \pm 11^{\dagger}$ & $197 \pm 12^{* \dagger}$ \\
\hline \multicolumn{6}{|c|}{ Cardiac output $\left(\mathrm{ml} \mathrm{min}{ }^{-1} \mathrm{~kg}^{-1}\right)$} \\
\hline Normal & 10 & $127 \pm 6$ & $188 \pm 7 *$ & $195 \pm 8 *$ & $212 \pm 9 *$ \\
\hline $\mathrm{DM}+\mathrm{HC}+\mathrm{CKD}$ & 8 & $107 \pm 4^{\dagger}$ & $150 \pm 7 * \dagger$ & $160 \pm 7 * \dagger$ & $150 \pm 22^{* \dagger}$ \\
\hline \multicolumn{6}{|c|}{ Stroke volume $\left(\mathrm{ml} \mathrm{kg}^{-1}\right)$} \\
\hline Normal & 10 & $1.07 \pm 0.05$ & $1.04 \pm 0.05$ & $0.96 \pm 0.06 *$ & $0.93 \pm 0.05 *$ \\
\hline $\mathrm{DM}+\mathrm{HC}+\mathrm{CKD}$ & 8 & $0.92 \pm 0.03^{\dagger}$ & $0.92 \pm 0.03$ & $0.92 \pm 0.03$ & $0.89 \pm 0.04$ \\
\hline \multicolumn{6}{|c|}{$\mathrm{LVdP} / \mathrm{d} t_{\max }\left(\mathrm{mmHg} \mathrm{s}^{-1}\right)$} \\
\hline Normal & 4 & $3390 \pm 230$ & $4660 \pm 660$ & $4970 \pm 760$ & $5310 \pm 700^{*}$ \\
\hline $\mathrm{DM}+\mathrm{HC}+\mathrm{CKD}$ & 7 & $2990 \pm 370$ & $3800 \pm 490^{*}$ & $4060 \pm 610^{*}$ & $4070 \pm 630^{*}$ \\
\hline \multicolumn{6}{|c|}{$\mathrm{LVdP} / \mathrm{d} t_{\min }\left(\mathrm{mmHg} \mathrm{s}^{-1}\right)$} \\
\hline Normal & 4 & $-2330 \pm 180$ & $-2740 \pm 210$ & $-3050 \pm 250$ & $-3450 \pm 300^{*}$ \\
\hline $\mathrm{DM}+\mathrm{HC}+\mathrm{CKD}$ & 7 & $-2360 \pm 200$ & $-2770 \pm 200^{*}$ & $-2910 \pm 220$ & $-2950 \pm 210^{*}$ \\
\hline \multicolumn{6}{|l|}{ mLAP (mmHg) } \\
\hline Normal & 9 & $6 \pm 1$ & $13 \pm 2 *$ & $15 \pm 1^{*}$ & $18 \pm 1 *$ \\
\hline $\mathrm{DM}+\mathrm{HC}+\mathrm{CKD}$ & 7 & $5 \pm 1$ & $9 \pm 1^{*}$ & $11 \pm 2 *^{\dagger}$ & $13 \pm 1 *^{\dagger}$ \\
\hline \multicolumn{6}{|l|}{ MAP (mmHg) } \\
\hline Normal & 10 & $89 \pm 2$ & $95 \pm 3^{*}$ & $98 \pm 3 *$ & $100 \pm 3^{*}$ \\
\hline $\mathrm{DM}+\mathrm{HC}+\mathrm{CKD}$ & 8 & $87 \pm 2$ & $94 \pm 3 *$ & $95 \pm 4^{*}$ & $96 \pm 2 *$ \\
\hline \multicolumn{6}{|c|}{$\operatorname{SVC}\left(\mathrm{ml} \mathrm{mmHg}{ }^{-1} \min ^{-1} \mathrm{~kg}^{-1}\right)$} \\
\hline Normal & 10 & $1.49 \pm 0.10$ & $2.02 \pm 0.14^{*}$ & $2.04 \pm 0.14 *$ & $2.16 \pm 0.16^{*}$ \\
\hline $\mathrm{DM}+\mathrm{HC}+\mathrm{CKD}$ & 8 & $1.27 \pm 0.06$ & $1.64 \pm 0.07 * \dagger$ & $1.72 \pm 0.07 *$ & $1.84 \pm 0.06^{*}$ \\
\hline \multicolumn{6}{|l|}{ Hemoglobin $\left(\mathrm{g} \mathrm{dL}^{-1}\right)$} \\
\hline Normal & 10 & $9.7 \pm 0.4$ & $10.9 \pm 0.5^{*}$ & $10.9 \pm 0.5^{*}$ & $11.2 \pm 0.4^{*}$ \\
\hline $\mathrm{DM}+\mathrm{HC}+\mathrm{CKD}$ & 8 & $9.5 \pm 0.4$ & $10.8 \pm 0.5^{*}$ & $11.0 \pm 0.3^{*}$ & $10.8 \pm 0.4^{*}$ \\
\hline \multicolumn{6}{|l|}{ Arterial $\mathrm{SaO}_{2}(\%)$} \\
\hline Normal & 10 & $98 \pm 1$ & $98 \pm 1$ & $97 \pm 1$ & $97 \pm 1$ \\
\hline $\mathrm{DM}+\mathrm{HC}+\mathrm{CKD}$ & 8 & $98 \pm 1$ & $97 \pm 1$ & $98 \pm 1$ & $98 \pm 1$ \\
\hline \multicolumn{6}{|c|}{ Mixed venous $\mathrm{SaO}_{2}(\%)$} \\
\hline Normal & 10 & $57 \pm 2$ & $39 \pm 2 *$ & $35 \pm 3 *$ & $29 \pm 2 *$ \\
\hline $\mathrm{DM}+\mathrm{HC}+\mathrm{CKD}$ & 8 & $50 \pm 1^{\dagger}$ & $34 \pm 1 *$ & $33 \pm 2 *$ & $28 \pm 2 *$ \\
\hline \multicolumn{6}{|c|}{$\mathrm{B} V \mathrm{O}_{2}\left(\mathrm{mmol} \mathrm{min}{ }^{-1} \mathrm{~kg}^{-1}\right)$} \\
\hline Normal & 10 & $0.33 \pm 0.03$ & $0.77 \pm 0.05^{*}$ & $0.84 \pm 0.07 *$ & $1.01 \pm 0.05^{*}$ \\
\hline $\mathrm{DM}+\mathrm{HC}+\mathrm{CKD}$ & 8 & $0.31 \pm 0.02$ & $0.66 \pm 0.05^{*}$ & $0.73 \pm 0.07 *$ & $0.80 \pm 0.06^{* \dagger}$ \\
\hline
\end{tabular}

Data are mean \pm SEM

$L V d P / d t_{\text {max }}$ maximum rate of rise of left ventricular pressure, $L V d P / d t_{\min }$ maximum rate of fall of left ventricular pressure, $m L A P$ mean left atrial pressure, MAP mean arterial pressure, $S V C$ systemic vascular conductance, $\mathrm{SaO}_{2}$ oxygen saturation, $\mathrm{BVO}_{2}$ body oxygen consumption

$* p<0.05$ versus rest within group

${ }^{\dagger} p<0.05$ versus corresponding Normal
$23.6 \pm 0.7$ vs. $26.7 \pm 0.3 \mathrm{mmol} \mathrm{L}^{-1}$ in $\mathrm{DM}+\mathrm{HC}+\mathrm{CKD}$ vs. Normal, $p=0.01$ ) were lower in $\mathrm{DM}+\mathrm{HC}+\mathrm{CKD}$ swine at rest and during low-intensity exercise, while arterial $\mathrm{pH}$ was not different between groups (Table 3), suggesting full respiratory compensation of metabolic acidosis.

\section{Myocardial oxygen balance, perfusion, and metabolism}

Compared to normal swine, $\mathrm{DM}+\mathrm{HC}+\mathrm{CKD}$ swine required higher levels of $\mathrm{MVO}_{2}$ for each level of cardiac 

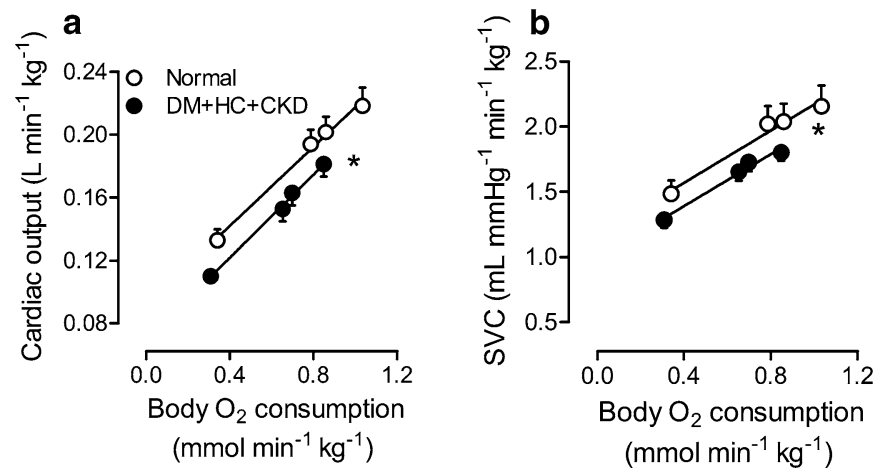

Fig. 3 Systemic exercise response in $\mathrm{DM}+\mathrm{HC}+\mathrm{CKD}$ and Normal swine. $\mathrm{DM}+\mathrm{HC}+\mathrm{CKD}$ swine show a lower cardiac output (a), a lower systemic vascular conductance (SVC b), a higher body oxygen $\left(\mathrm{O}_{2}\right)$ extraction (c), and higher arterial lactate levels (d) for the same

work, particularly during exercise, reflecting decreased myocardial efficiency (Fig. 4a). The higher levels of $\mathrm{MVO}_{2}$ in $\mathrm{DM}+\mathrm{HC}+\mathrm{CKD}$ swine were not fully met by commensurate increases in coronary blood flow (Fig. 4b) and myocardial $\mathrm{O}_{2}$ delivery (Fig. 4c), necessitating an increase in myocardial oxygen extraction (Fig. 4d), that resulted in reductions in coronary venous $p \mathrm{O}_{2}$ (Fig. 4e) and coronary venous $\mathrm{SaO}_{2}$ (Fig. 4f) in $\mathrm{DM}+\mathrm{HC}+\mathrm{CKD}$ compared to Normal swine, both at rest and during exercise. Consistent with the impaired myocardial $\mathrm{O}_{2}$ delivery during exercise, a decrease in myocardial lactate extraction for a given level of myocardial oxygen consumption (Fig. $4 \mathrm{~g}$ ) or myocardial lactate consumption for a given level of myocardial lactate delivery (Fig. 4h) was observed in DM + HC + CKD swine compared to Normal, suggestive of anaerobic metabolism.

\section{Coronary flow reserve, structure, and endothelial function}

Consistent with an impaired recruitment of vasodilator reserve during exercise in $\mathrm{DM}+\mathrm{HC}+\mathrm{CKD}$, CFR was reduced by $25 \%$ from $3.64 \pm 0.24$ in Normal to $2.69 \pm 0.27$ in $\mathrm{DM}+\mathrm{HC}+\mathrm{CKD}$ swine $(p=0.038)$, which appeared to be principally due to a small increase in basal flow while maximal flow was unaltered (Fig. 5). The latter was consistent with the lack of alterations in morphology or density of left ventricular small arterioles, evidenced by similar perivascular collagen content (Fig. 6a-c), media-to-lumen ratios (Fig. 6d-f) and arteriolar densities (Fig. 6g-i) between groups. Interestingly, coronary microvascular function measurements in vitro confirmed coronary microvascular endothelial dysfunction as vasodilation to bradykinin was blunted in DM + HC + CKD compared to Normal (Fig. 7a), while vascular smooth muscle cell function was maintained (Fig. 7b).
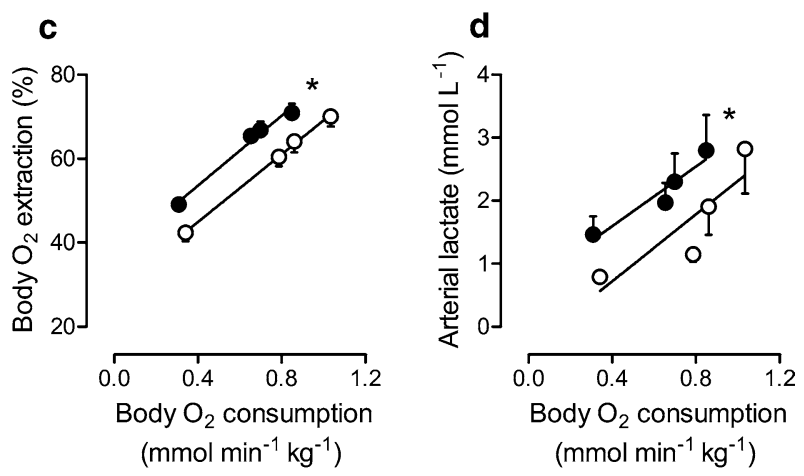

level of body oxygen consumption as compared to Normal. Data are mean \pm SEM. DM $+\mathrm{HC}+\mathrm{CKD} n=8$ and Normal $n=10$. ${ }^{*} p<0.05$ $\mathrm{DM}+\mathrm{HC}+\mathrm{CKD}$ versus Normal by repeated measures two-way ANCOVA

\section{Left ventricular function}

The perturbations in myocardial oxygen balance in $\mathrm{DM}+\mathrm{HC}+\mathrm{CKD}$ swine were associated with a lower stroke volume, both at rest and during exercise (Fig. 8a), as well as a trend towards a lower $\mathrm{LVdP} / \mathrm{d} t_{\max }$ during exercise (Fig. 8b). No differences were observed in $\mathrm{LVdP} / \mathrm{d} t_{\min }$ (Fig. 8c) or left atrial pressure (Fig. 8d), either at rest or during exercise, between the two groups.

\section{Discussion}

The present study tested the hypothesis that prolonged exposure to comorbidities results in perturbations in myocardial blood flow and oxygen delivery, leading to a shift towards anaerobic metabolism and cardiac dysfunction in exercising swine. The main findings were that (i) the combination of diabetes mellitus, hypercholesterolemia and chronic kidney disease resulted in lower cardiac output at rest and during exercise, which was accompanied by impaired systemic vasodilatation and increased circulating levels of lactate. (ii) Exposure to these comorbidities resulted in increased levels of oxygen consumption at similar levels of cardiac work, indicating reduced myocardial efficiency. (iii) The comorbidities also resulted in perturbations in myocardial perfusion and oxygen delivery, at a time when coronary atherosclerosis was negligible. (iv) The perturbations in myocardial oxygen balance were associated with lower lactate consumption and reductions in stroke volume and $\mathrm{LVdP} / \mathrm{d} t_{\max }$, suggestive of myocardial ischemia and dysfunction. (v) Adenosine-recruitable coronary flow reserve was reduced, which was due to an increase in basal resting coronary blood flow per gram of myocardium. In contrast, maximal coronary blood flow per gram of myocardium was not altered, consistent with maintained arteriolar densities 
Table 3 Myocardial metabolism of $\mathrm{DM}+\mathrm{HC}+\mathrm{CKD}$ and

Normal swine at rest and during treadmill exercise

\begin{tabular}{|c|c|c|c|c|c|}
\hline & \multirow[b]{2}{*}{$n$} & \multirow[t]{2}{*}{ Rest } & \multicolumn{3}{|c|}{ Exercise $\left(\mathrm{km} \mathrm{h}^{-1}\right)$} \\
\hline & & & 2 & 3 & 4 \\
\hline \multicolumn{6}{|l|}{ Arterial $\mathrm{SaO}_{2}(\%)$} \\
\hline Normal & 9 & $98 \pm 1$ & $98 \pm 1$ & $97 \pm 1$ & $97 \pm 1$ \\
\hline $\mathrm{DM}+\mathrm{HC}+\mathrm{CKD}$ & 8 & $98 \pm 1$ & $97 \pm 1$ & $99 \pm 1$ & $98 \pm 1$ \\
\hline \multicolumn{6}{|c|}{ Coronary venous $\mathrm{SaO}_{2}(\%)$} \\
\hline Normal & 9 & $22 \pm 1$ & $23 \pm 1$ & $20 \pm 1$ & $20 \pm 2$ \\
\hline $\mathrm{DM}+\mathrm{HC}+\mathrm{CKD}$ & 8 & $17 \pm 1^{\dagger}$ & $16 \pm 1^{\dagger}$ & $16 \pm 1$ & $15 \pm 1^{\dagger}$ \\
\hline \multicolumn{6}{|l|}{ Arterial $p \mathrm{O}_{2}(\mathrm{mmHg})$} \\
\hline Normal & 9 & $109 \pm 4$ & $102 \pm 5^{*}$ & $101 \pm 5^{*}$ & $99 \pm 4 *$ \\
\hline $\mathrm{DM}+\mathrm{HC}+\mathrm{CKD}$ & 8 & $110 \pm 3$ & $101 \pm 3 *$ & $108 \pm 5$ & $107 \pm 5$ \\
\hline \multicolumn{6}{|c|}{ Coronary venous $p \mathrm{O}_{2}(\mathrm{mmHg})$} \\
\hline Normal & 9 & $24 \pm 1$ & $25 \pm 1$ & $24 \pm 1$ & $24 \pm 1$ \\
\hline $\mathrm{DM}+\mathrm{HC}+\mathrm{CKD}$ & 8 & $20 \pm 1^{\dagger}$ & $21 \pm 1^{\dagger}$ & $21 \pm 1^{\dagger}$ & $20 \pm 1^{\dagger}$ \\
\hline \multicolumn{6}{|c|}{ Arterial lactate $\left(\mathrm{mmol} \mathrm{L}^{-1}\right)$} \\
\hline Normal & 9 & $0.76 \pm 0.08$ & $1.12 \pm 0.12 *$ & $1.89 \pm 0.45^{*}$ & $2.83 \pm 0.70^{*}$ \\
\hline $\mathrm{DM}+\mathrm{HC}+\mathrm{CKD}$ & 8 & $1.84 \pm 0.50^{\dagger}$ & $2.56 \pm 0.74$ & $2.93 \pm 0.88$ & $3.85 \pm 1.39$ \\
\hline \multicolumn{6}{|c|}{ Coronary venous lactate $\left(\mathrm{mmol} \mathrm{L}^{-1}\right)$} \\
\hline Normal & 9 & $0.36 \pm 0.04$ & $0.81 \pm 0.23$ & $1.19 \pm 0.32$ & $1.95 \pm 0.54 *$ \\
\hline $\mathrm{DM}+\mathrm{HC}+\mathrm{CKD}$ & 8 & $1.76 \pm 0.49^{\dagger}$ & $1.98 \pm 0.63$ & $2.65 \pm 0.96$ & $3.28 \pm 1.44$ \\
\hline \multicolumn{6}{|l|}{ Arterial $\mathrm{pH}$} \\
\hline Normal & 9 & $7.44 \pm 0.01$ & $7.46 \pm 0.01 *$ & $7.46 \pm 0.01 *$ & $7.46 \pm 0.01 *$ \\
\hline $\mathrm{DM}+\mathrm{HC}+\mathrm{CKD}$ & 8 & $7.43 \pm 0.01$ & $7.46 \pm 0.01 *$ & $7.47 \pm 0.01 *$ & $7.47 \pm 0.01 *$ \\
\hline \multicolumn{6}{|l|}{ Coronary venous $\mathrm{pH}$} \\
\hline Normal & 9 & $7.36 \pm 0.01$ & $7.35 \pm 0.01$ & $7.35 \pm 0.01$ & $7.33 \pm 0.01$ \\
\hline $\mathrm{DM}+\mathrm{HC}+\mathrm{CKD}$ & 8 & $7.36 \pm 0.01$ & $7.38 \pm 0.01$ & $7.38 \pm 0.02^{\dagger}$ & $7.36 \pm 0.02$ \\
\hline \multicolumn{6}{|c|}{ Arterial $p \mathrm{CO}_{2}(\mathrm{mmHg})$} \\
\hline Normal & 9 & $39 \pm 1$ & $37 \pm 1^{*}$ & $36 \pm 1^{*}$ & $35 \pm 1^{*}$ \\
\hline $\mathrm{DM}+\mathrm{HC}+\mathrm{CKD}$ & 8 & $36 \pm 1^{\dagger}$ & $34 \pm 1^{\dagger}$ & $31 \pm 1^{* \dagger}$ & $30 \pm 1^{* \dagger}$ \\
\hline \multicolumn{6}{|c|}{ Coronary venous $p \mathrm{CO}_{2}(\mathrm{mmHg})$} \\
\hline Normal & 9 & $51 \pm 1$ & $50 \pm 2$ & $50 \pm 2$ & $48 \pm 2$ \\
\hline $\mathrm{DM}+\mathrm{HC}+\mathrm{CKD}$ & 8 & $46 \pm 1^{\dagger}$ & $44 \pm 1^{\dagger}$ & $42 \pm 1 *^{\dagger}$ & $44 \pm 2 *$ \\
\hline \multicolumn{6}{|c|}{$\mathrm{M} V \mathrm{O}_{2}\left(\mu \mathrm{mol} \min ^{-1} \mathrm{~g}^{-1}\right)$} \\
\hline Normal & 9 & $5.6 \pm 0.4$ & $8.5 \pm 0.5^{*}$ & $9.5 \pm 0.5 *$ & $11.1 \pm 0.7^{*}$ \\
\hline $\mathrm{DM}+\mathrm{HC}+\mathrm{CKD}$ & 7 & $6.5 \pm 0.9$ & $10.5 \pm 1.6^{*}$ & $11.5 \pm 1.6^{*}$ & $12.6 \pm 1.8^{*}$ \\
\hline
\end{tabular}

Data are mean \pm SEM

$\mathrm{SaO}_{2}$ oxygen saturation, $\mathrm{pO}_{2}$ partial pressure of oxygen, $\mathrm{pCO}_{2}$ partial pressure of carbon dioxide, $\mathrm{MVO}_{2}$ myocardial oxygen consumption per gram of myocardium

$* p<0.05$ versus rest within group

${ }^{\dagger} p<0.05$ versus corresponding Normal and wall/lumen ratios and maintained perivascular collagen content. (vi) Coronary small arteries demonstrated selective blunting of endothelium-dependent vasodilation. The implications of these findings will be discussed.

\section{Coronary microvascular dysfunction}

The presence of risk factors, including DM, HC and CKD, has been associated with CMD and INOCA in both experimental [5, 57, 63] and clinical [2, 41, 42, 44] studies. For example, we previously showed that CMD was already present in swine 2.5 months after the induction of DM and $\mathrm{HC}$ in the absence of coronary atherosclerosis [63]. Furthermore, CMD remained present in swine with 15 -month diabetes and hypercholesterolemia with modest non-obstructive atherosclerosis [57], and was also found in a swine model of familial hypercholesterolemia (FH) with moderate (20-60\%) coronary plaque burden [5]. Here, we observed coronary microvascular endothelial dysfunction in isolated small arteries studied ex vivo, in the absence of atherosclerosis 


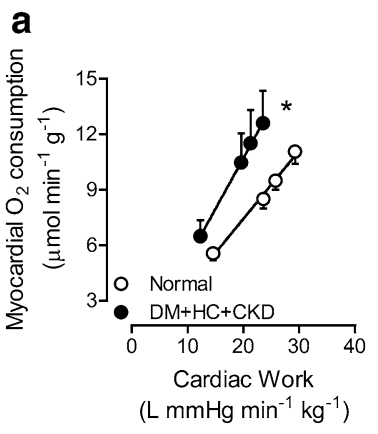

e

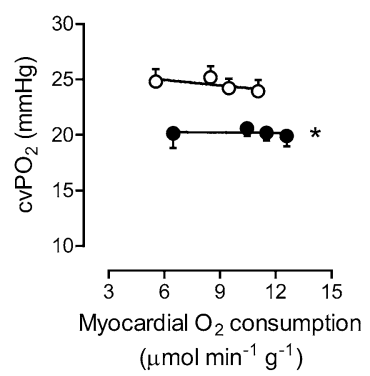

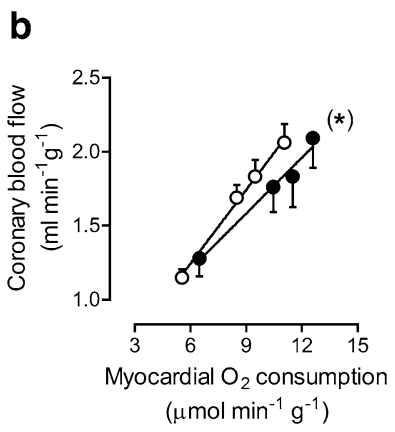

f

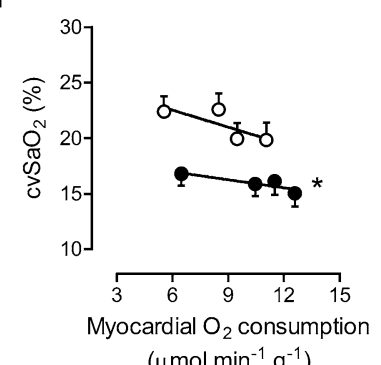

$\left(\mu \mathrm{mol} \mathrm{min}{ }^{-1} \mathrm{~g}^{-1}\right)$

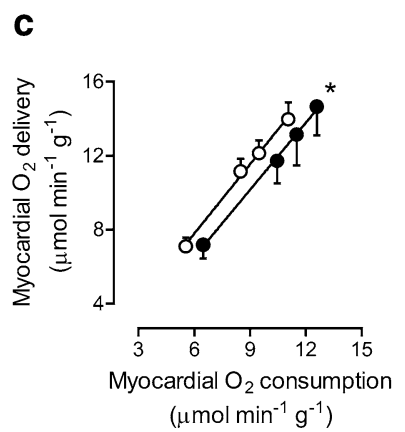

d

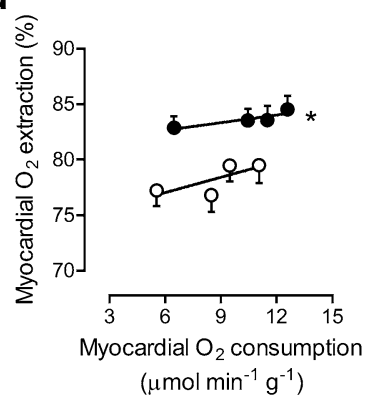

g
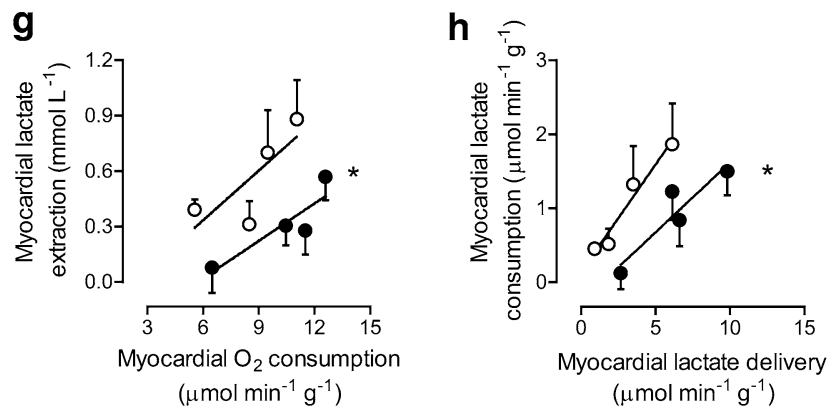

Fig. 4 Myocardial blood flow and oxygen balance in $\mathrm{DM}+\mathrm{HC}+\mathrm{CKD}$ and Normal swine at rest and during graded treadmill exercise. Myocardium of $\mathrm{DM}+\mathrm{HC}+\mathrm{CKD}$ swine shows increased oxygen consumption for the same level of cardiac work (a), a trend towards impaired coronary blood flow especially during exercise (b), have a lower myocardial oxygen delivery (c), and a higher oxygen extraction (d), which results in lower coronary venous oxygen pressure $\left(\mathrm{cvPO} \mathrm{O}_{2}\right.$ e) and coronary venous oxygen satura-

which is in line with our previous study [54]. Taken together, these studies indicate that CMD is present well before coronary atherosclerosis occurs and remains present once the process of atherosclerosis advances.
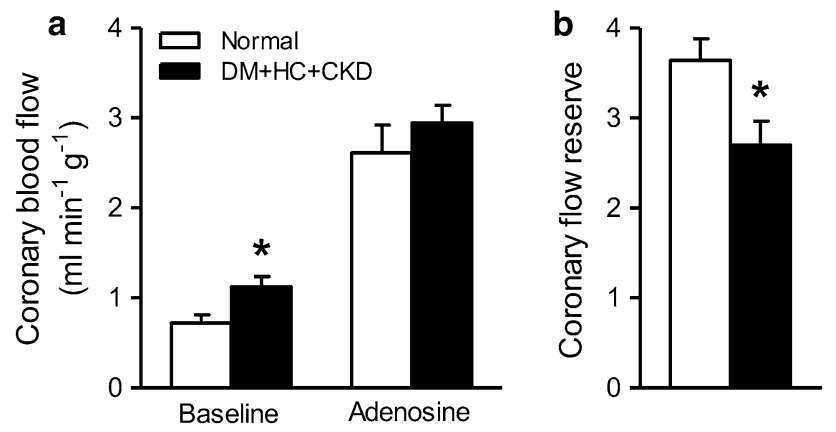

Fig. 5 Coronary blood flow during baseline conditions and during maximal vasodilation to adenosine (a) resulting in a decrease in coronary flow reserve in $\mathrm{DM}+\mathrm{HC}+\mathrm{CKD}$ (b) compared to Normal swine at rest and awake state. Data are mean \pm SEM. DM $+\mathrm{HC}+\mathrm{CKD}$ : $n=4$, Normal: $n=4$. ${ }^{*} p<0.05 \mathrm{DM}+\mathrm{HC}+\mathrm{CKD}$ versus Normal by unpaired $t$ test tion $\left(\mathrm{cvSaO}_{2} \mathbf{f}\right)$. Lower myocardial lactate extraction $(\mathbf{g})$ and lower myocardial lactate consumption for a given level of myocardial lactate delivery (h) were measured in $\mathrm{DM}+\mathrm{HC}+\mathrm{CKD}$ as compared to Normal animals. Data are mean \pm SEM. DM + HC +CKD: $n=7-8$, Normal: $n=9$. $* p<0.05 \mathrm{DM}+\mathrm{HC}+\mathrm{CKD}$ versus Normal, $(*) p<0.1$ $\mathrm{DM}+\mathrm{HC}+\mathrm{CKD}$ versus Normal by repeated measures two-way ANCOVA

The present study in chronically instrumented swine demonstrates that comorbidities can cause significant perturbations in myocardial oxygen balance both at rest and particularly during exercise. Thus, $\mathrm{DM}+\mathrm{HC}+\mathrm{CKD}$ animals demonstrated increased myocardial oxygen consumption at a given level of cardiac work, particularly during exercise, causing a counterclockwise rotation in the relation between cardiac work and oxygen consumption (Fig. 4a). This reduced myocardial efficiency in DM $+\mathrm{HC}+\mathrm{CKD}$ is commonly seen in metabolic disorders, including diabetes and dyslipidemia $[5,7,23]$. The mechanisms underlying the observed myocardial inefficiency in $\mathrm{DM}+\mathrm{HC}+\mathrm{CKD}$ swine were not investigated in the present study, but could be several-fold. First, a myocardial substrate shift towards free fatty acid utilization leading to a reduced phosphate/oxygen ratio could have contributed to the increased oxygen consumption $[7,11,26]$. Second, and more likely, mitochondrial uncoupling [7, 11, 23, 52], possibly due to oxidative stress [7], could also lead to a decrease in phosphate/oxygen ratio, thereby increasing oxygen consumption at a given level of cardiac work.

Although mitochondrial function was not measured in the present study, a direct link between cardiac mitochondrial 
a

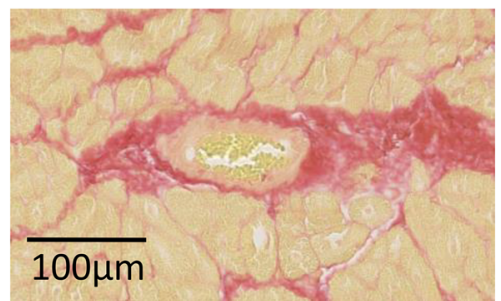

b

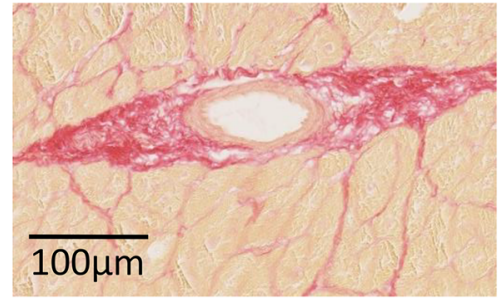

C

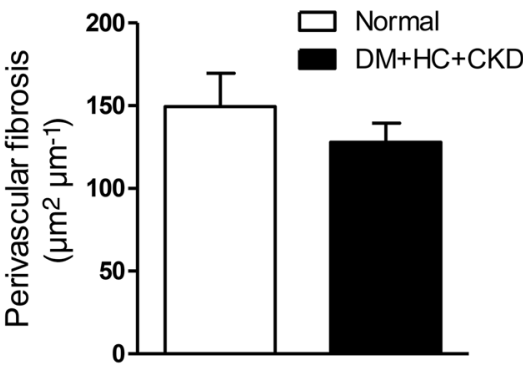

d

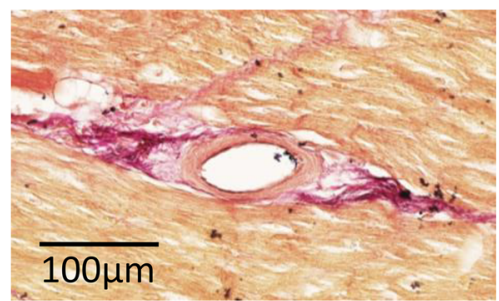

e

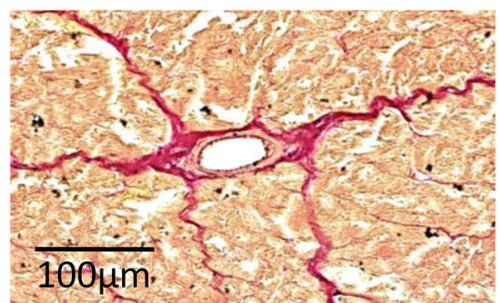

f

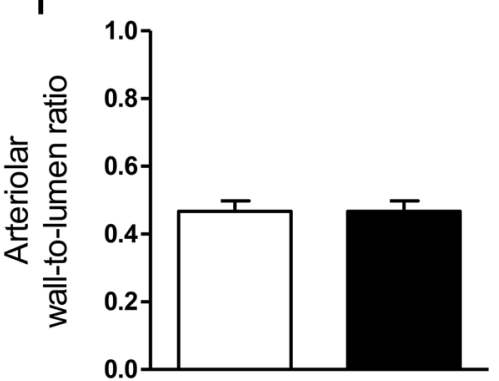

g

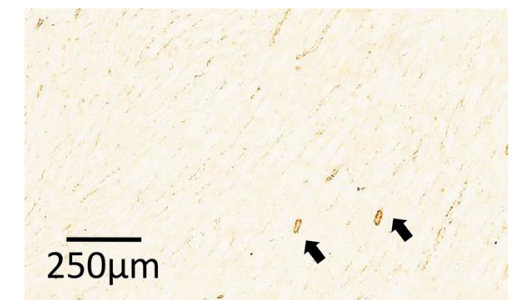

h

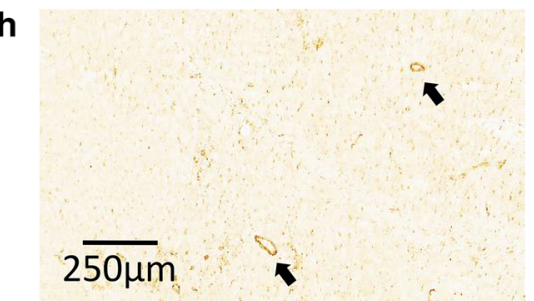

i

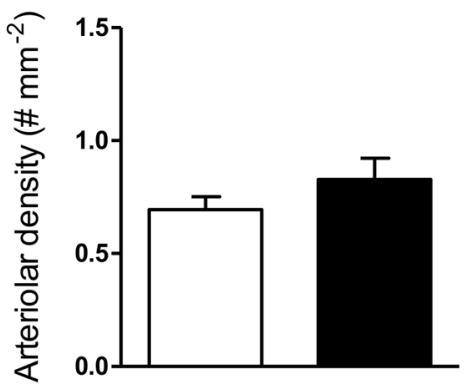

Fig. 6 Typical examples of small arterioles $(<100 \mu \mathrm{m})$ stained with picrosirius red staining of Normal (a) and DM $+\mathrm{HC}+\mathrm{CKD}(\mathbf{b})$ and perivascular fibrosis quantification as area collagen corrected for lumen diameter $(\mathbf{c})$. Typical examples of small arterioles $(<100 \mu \mathrm{m})$ stained with resorcin-fuchsin of Normal (d) and DM + HC + CKD (e) and media thickness corrected for lumen diameter (f). Typical examples of small arterioles stained for smooth muscle actin of Normal (g) and $\mathrm{DM}+\mathrm{HC}+\mathrm{CKD}(\mathbf{h})$ and quantification of coronary arteriolar density $(<100 \mu \mathrm{m}$, i). Normal $n=10$, DM $+\mathrm{HC}+\mathrm{CKD} n=7$. Data are mean \pm SEM

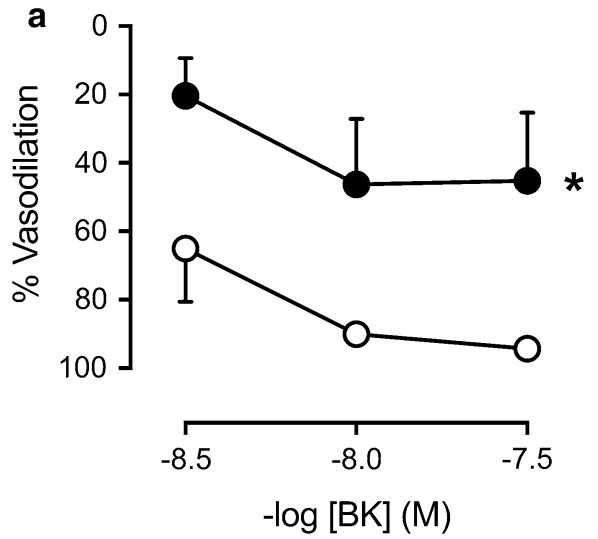

Fig. 7 Ex vivo endothelium-dependent and endothelium-independent vasoreactivity of coronary microvessels. Small coronary arteries $(\sim 300 \mu \mathrm{m})$ of $\mathrm{DM}+\mathrm{HC}+\mathrm{CKD}$ have impaired bradykinin (BK)induced vasodilation, suggesting endothelial dysfunction (a), while endothelium-independent vasodilation to nitric oxide donor sodium

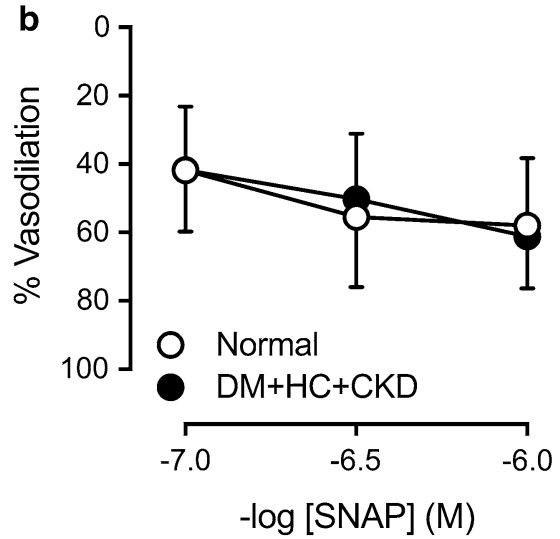

nitroprusside (SNAP) was unaltered, indicating maintained vascular smooth muscle cell function (b). Normal $n=3$ and DM + HC +CKD $n=3$. Data are mean \pm SEM. Error bars are presented but might be too small to be visible. ${ }^{*} p<0.05 \mathrm{DM}+\mathrm{HC}+\mathrm{CKD}$ versus Normal by repeated measures two-way ANOVA 

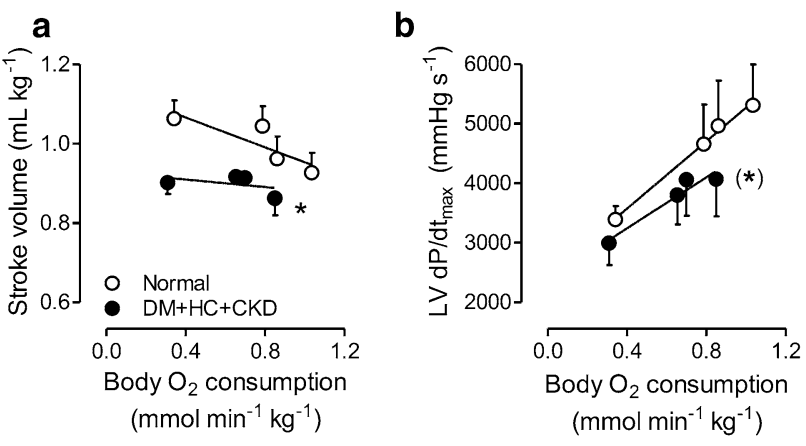

Fig. 8 Left ventricular function in $\mathrm{DM}+\mathrm{HC}+\mathrm{CKD}$ and Normal swine at rest and during graded treadmill exercise. DM $+\mathrm{HC}+\mathrm{CKD}$ swine have a lower stroke volume (a), a trend towards an impaired left ventricular systolic function $\left(\mathrm{LVdP} / \mathrm{dt}_{\max }, \mathbf{b}\right)$, similar left ventricular diastolic function $\left(\mathrm{LVdP} / \mathrm{d} t_{\min }, \mathbf{c}\right)$ for the identical body oxygen consumption levels, and similar mean left atrial pressures for the same level of cardiac output (d) compared to Normal. Stroke

dysfunction and microvascular dysfunction in animal models of metabolic disease was recently proposed [5, 23]. In accordance with this concept, we observed a reduction in CFR of approximately $25 \%$ in DM + HC + CKD swine, as compared to Normal swine, which was principally due to an increase in basal coronary blood flow as a result of an increase in myocardial oxygen consumption. Strikingly, maximal myocardial blood flow was maintained, which was in accordance with the normal arteriolar morphology and density, and unaltered peri-arteriolar collagen content. Our finding of a reduction in CFR due to an increase in basal coronary flow, rather than a decrease in maximal flow, is also in good agreement with observations in a variety of patient groups. Thus, in INOCA patients with functional CMD [50], in patients with residual CMD after undergoing percutaneous coronary intervention for obstructive CAD [27], and in patients with diabetes mellitus [46], an increase in basal coronary blood flow per gram of myocardium [50] or increases in basal coronary flow velocity $[27,46]$, as compared to healthy individuals, appears primarily responsible for the reduction in CFR. Moreover, patients with a reduced CFR and an increased basal blood flow demonstrate an increased cardiovascular mortality risk compared to patients with normal basal coronary blood flow and CFR [24]. Also, among patients with diabetes, women had a lower CFR than men due to higher basal myocardial blood flow [25]. Interestingly, the increase in basal myocardial blood flow correlated with diastolic dysfunction in women, but not in men, while CFR did not correlate with diastolic dysfunction in either sex [25]. In light of these observations, it was recently proposed that basal myocardial blood flow could represent a potentially superior marker of CMD in certain pathological settings [4].
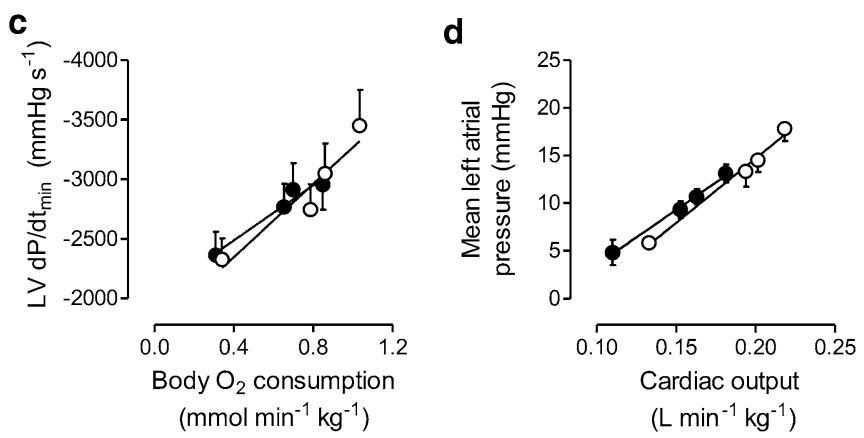

volume, mean left atrial pressure and cardiac output measurements: $\mathrm{DM}+\mathrm{HC}+\mathrm{CKD} n=8$ and Normal $n=10 ; \mathrm{LVdP} / \mathrm{d} t_{\max }$ and LVdP/ $\mathrm{d} t_{\text {min }}: \mathrm{DM}+\mathrm{HC}+\mathrm{CKD} n=7$ Normal $n=4$. Data are mean $\pm \mathrm{SEM}$. $*^{*} p<0.05 \quad \mathrm{DM}+\mathrm{HC}+\mathrm{CKD}$ versus Normal, $\quad\left(^{*}\right) p=0.053$ $\mathrm{DM}+\mathrm{HC}+\mathrm{CKD}$ versus Normal by repeated measures two-way ANCOVA

The present study further shows that the basal higher oxygen consumption in $\mathrm{DM}+\mathrm{HC}+\mathrm{CKD}$ was not fully met by a commensurate increase in myocardial oxygen delivery, which necessitated an increase in myocardial oxygen extraction, resulting in lower levels of coronary venous oxygen content. Cardiovascular comorbidities can cause perturbations in myocardial oxygen delivery by affecting the coronary circulation at different levels, including proximal obstructive CAD, distal small artery and arteriolar dysfunction and remodeling, and alterations in capillary structure and function [43]. In the present study, the increase in oxygen extraction occurred in the absence of coronary atherosclerosis and despite a reduction in capillary density, which acts to reduce oxygen extraction capacity [43]. Moreover, coronary microvascular structure and maximal coronary blood flow per gram of myocardium were maintained. Hence, the increased oxygen extraction most likely reflects perturbations in the regulation of resistance vessel tone-likely involving endothelial dysfunction-resulting in impaired myocardial blood flow and oxygen delivery in the face of increased oxygen consumption [17, 43].

The perturbations in myocardial oxygen delivery were accompanied by a reduction in lactate consumption-particularly during exercise-indicating a shift towards anaerobic metabolism, suggestive of myocardial ischemia [28]. Although the reduction in lactate consumption may, in part, be caused by a DM-induced reduction in pyruvate dehydrogenase activity [22], in three out of eight DM + HC + CKD swine, we observed net lactate production under resting conditions, which can only be explained by anaerobic metabolism [28]. Our observations are consistent with the concept that $\mathrm{CMD}$, in the absence of coronary atherosclerosis, can impair myocardial oxygenation severely enough to produce myocardial ischemia [13, 32, 44, 47, 53, 59]. Furthermore, 
these findings are in agreement with accumulating clinical evidence that myocardial ischemia can also occur in the absence of obstructive CAD, termed INOCA [2, 40, 44, 47, 59], indicating that swine with $\mathrm{DM}+\mathrm{HC}+\mathrm{CKD}$ represent a bona fide large animal model of INOCA.

\section{Coronary microvascular dysfunction and diastolic dysfunction}

There is increasing evidence that comorbidities such as DM, dyslipidemia and CKD are linked not only to INOCA [2, 8,13 ] but also to the development of diastolic dysfunction and heart failure with preserved ejection fraction (HFpEF), involving endothelial dysfunction [45]. It has thus been proposed that INOCA and HFpEF both originate from CMD but that the paracrine effect of endothelial dysfunction is exerted on distinctive cell types, i.e., arteriolar vascular smooth muscle cells in INOCA versus cardiomyocytes in HFpEF, respectively [12]. Although we did not observe perturbations in active left ventricular relaxation, as evidenced by the maintained relation between $\mathrm{LVdP} / \mathrm{d} t_{\min }$ and body $\mathrm{O}_{2}$ consumption, we observed in our previous study (using the same animal model), an increase in left ventricular passive stiffness evidenced by an increase in the slope of the end-diastolic pressure volume relation, in the presence of a maintained ejection fraction [54]. The present study in the same animal model shows that not only capillary rarefaction but also impaired regulation of myocardial perfusion by the coronary resistance vessels occurs, which is associated with endothelial dysfunction. These experimental findings are in agreement with recent clinical studies, demonstrating the coexistence of diastolic dysfunction or HFpEF and microvascular angina $[12,41,60]$. Reduced coronary or myocardial flow reserve, independent of coronary artery stenosis, is considered to be a marker of microvascular endothelial dysfunction and is present in patients with HFpEF or diastolic dysfunction $[16,58,60]$. Thus, the common denominator linking HFpEF and INOCA appears to be CMD induced by comorbidities [20,39, 45].

Our DM $+\mathrm{HC}+\mathrm{CKD}$ swine model represents a model of early diastolic dysfunction (or pre-HFpEF), as left atrial pressures were not elevated either at rest or during exercise. Nevertheless, cardiac output was decreased which was due to a decrease in stroke volume as well as to chronotropic incompetence, i.e., limited capacity of the $\mathrm{DM}+\mathrm{HC}+\mathrm{CKD}$ swine to increase their heart rate during exercise. The latter is a common feature seen in HFpEF patients with CKD [34], as well as diabetic patients [33]. Chronotropic incompetence is thought to be the result of downregulation and/or desensitization of myocardial $\beta$-adrenergic receptors due to increased levels of catecholamines [6]. Although the HFpEF phenotype was still mild, advanced CMD was already present, indicating that CMD may precede advanced diastolic dysfunction and HFpEF. This was also suggested by a recent clinical study showing that in patients with a reduced CFR, diastolic function worsens progressively over time and is associated with an increased risk of HFpEF hospitalization [60]. Taken together, these findings are consistent with the concept of CMD being the primary defect that subsequently leads to diastolic dysfunction, eventually progressing to overt HFpEF.

\section{Methodological considerations}

Although several large and small animal models (for CMD) have been described, no single animal model perfectly emulates the human disease [56]. In the present study, CMD was induced by prolonged exposure to diabetes, high-fat diet and CKD, comorbidities commonly observed in patients with INOCA [2]. A type 2-like DM phenotype, with significant hyperglycemia, was induced using multiple low-dose streptozotocin injections combined with a high-fat and high-fructose diet, as previously described [21, 48, 54, 56, 57, 63]. Although disease development differs from the slow-onset of DM type 2 in humans, this approach produces sustained hyperglycemia without insulin dependency and results in progressive insulin resistance [54, 57, 63]. Moreover, in conjunction with the high-fat and high-fructose diet, this experimental approach results in dyslipidemia $[54,56,57$, 63], thereby mimicking several features of metabolic dysregulation as observed in the clinical setting.

It is increasingly recognized that CKD is an important risk factor for the development of CMD [3, 49]. The exact mechanisms of the detrimental effects of CKD on coronary microvascular function are incompletely understood, but low-grade inflammation and increased circulation of uremic toxins are proposed to play a role [62]. In humans, CKD is often the result of local renal inflammation, hypoxia, and loss of glomeruli and tubuli, with subsequent hyperfiltration of healthy regions, resulting in a vicious cycle of progressive kidney damage [61]. Animal models of renovascular hypertension, 5/6 nephrectomy, and unilateral ureteric obstruction have been used by other investigators to mimic various aspects of CKD [35, 51]. Here, partial renal microembolization with microspheres was used to induce CKD. This method results in glomerulosclerosis and tubulointerstitial damage not only in the embolized areas, but also in the remodeled, non-embolized upper pole of the left kidney [54]. These key features of human CKD resulted in a reduced GFR, measured by gold-standard inulin clearance, and increased creatinine levels. The combination of DM, $\mathrm{HC}$, and CKD resulted in a phenotype resembling INOCA in humans. However, the specific contribution of the individual factors and their potential synergistic action remains to be established. 
The present study further demonstrates that functional changes in the coronary microvasculature are already present well before overt plaque formation occurs. These early changes result in an impaired myocardial oxygen balance and reduced cardiac efficiency. The observation in a small group of animals that endothelial function in isolated coronary small arteries was perturbed, suggests a role for the loss of nitric oxide in mediating the impairments in myocardial oxygenation in $\mathrm{DM}+\mathrm{HC}+\mathrm{CKD}$ animals. Future studies should focus in more detail on the mechanisms underlying the increased myocardial oxygen consumption as well as the perturbations in oxygen delivery.

Although our data provide valuable information regarding the mechanisms of CMD at this early stage, without the influence of proximal obstructive CAD possibly affecting the distal microvasculature [55], it is increasingly recognized that there may be an interaction between non-obstructive and obstructive CAD. Thus, CMD may induce a decrease in shear stress in the large vessels and aggravate proximal $\mathrm{CAD}$, whereas proximal CAD may further induce CMD, potentially mediated by multiple processes involving microembolization and the release of vasoconstrictors [29, 37, 55]. Investigation of such interaction of obstructive CAD with CMD, by combining a chronic proximal coronary artery stenosis $[37,55]$ with the current model of comorbiditiesinduced CMD, should be the topic of future studies. Such studies should then also include the assessment of flow distribution across the left ventricular wall, as the presence of a coronary artery stenosis causes a regional flow redistribution away from the subendocardium towards the subepicardium [17], whereas comorbidities in the absence of obstructive CAD appear to result in more diffuse and transmurally homogeneous reductions in myocardial blood flow [5, 38, 50].

\section{Conclusion}

The present study is the first to investigate the effects of three common risk factors on myocardial oxygen balance in swine at rest and during graded treadmill exercise. Our findings demonstrate that, in the absence of coronary atherosclerosis, comorbidities can result in CMD that is severe enough to critically impair myocardial oxygenation, thereby resulting in anaerobic metabolism. Thus, our DM $+\mathrm{HC}+\mathrm{CKD}$ swine model represents a bona fide large animal model of INOCA. A link between CMD and left ventricular diastolic dysfunction has recently been shown in clinical studies. In our model, overt CMD is present at a time when diastolic dysfunction is still modest [54]. These findings are in agreement with clinical observations $[12,41,60]$ and support the concept that CMD is one of the drivers of diastolic dysfunction in patients with comorbidities, suggesting that CMD represents a prime target for therapeutic interventions in INOCA as well as diastolic dysfunction/HFpEF.

Acknowledgements The authors thank Annemarie Verzijl, Esther van de Kamp, Ilona Krabbendam, Lau Blonden, (ErasmusMC, Rotterdam, The Netherlands), Adele Dijk, Krista den Ouden, and Petra de Bree (UMC Utrecht, Utrecht, The Netherlands) for their expert technical support.

Funding This study was supported by grants from the European Commission FP7-Health-2010 Grant MEDIA-261409, the German Center for Cardiovascular Research (DZHK; $81 Z 0600207$ to DM), and the Netherlands CardioVascular Research Initiative: an initiative with support of the Dutch Heart Foundation [CVON2012-08 (PHAEDRA), CVON2014-11 (RECONNECT)].

Open Access This article is licensed under a Creative Commons Attribution 4.0 International License, which permits use, sharing, adaptation, distribution and reproduction in any medium or format, as long as you give appropriate credit to the original author(s) and the source, provide a link to the Creative Commons licence, and indicate if changes were made. The images or other third party material in this article are included in the article's Creative Commons licence, unless indicated otherwise in a credit line to the material. If material is not included in the article's Creative Commons licence and your intended use is not permitted by statutory regulation or exceeds the permitted use, you will need to obtain permission directly from the copyright holder. To view a copy of this licence, visit http://creativecommons.org/licenses/by/4.0/.

\section{References}

1. Anderson RD, Pepine CJ (2015) The coronary microcirculation in STEMI: the next frontier? Eur Heart J 36:3178-3181. https:// doi.org/10.1093/eurheartj/ehv495

2. Bairey Merz CN, Pepine CJ, Walsh MN, Fleg JL (2017) Ischemia and no obstructive coronary artery disease (INOCA): developing evidence-based therapies and research agenda for the next decade. Circulation 135:1075-1092. https://doi.org/10.1161/CIRCU LATIONAHA.116.024534

3. Bajaj NS, Singh A, Zhou W, Gupta A, Fujikura K, Byrne C, Harms HJ, Osborne MT, Bravo P, Andrikopoulou E, Divakaran S, Bibbo CF, Hainer J, Skali H, Taqueti V, Steigner M, Dorbala S, Charytan DM, Prabhu SD, Blankstein R, Deo RC, Solomon SD, Di Carli MF (2019) Coronary microvascular dysfunction, left ventricular remodeling and clinical outcomes in patients with chronic kidney impairment. Circulation. https://doi.org/10.1161/ circulationaha.119.043916

4. Bender SB (2019) Linking coronary microvascular and cardiac diastolic dysfunction in diabetes: are women more vulnerable? Diabetes 68:474-475. https://doi.org/10.2337/dbi18-0053

5. Bender SB, de Beer VJ, Tharp DL, Bowles DK, Laughlin MH, Merkus D, Duncker DJ (2016) Severe familial hypercholesterolemia impairs the regulation of coronary blood flow and oxygen supply during exercise. Basic Res Cardiol 111:61. https://doi. org/10.1007/s00395-016-0579-9

6. Borlaug BA (2014) The pathophysiology of heart failure with preserved ejection fraction. Nat Rev Cardiol 11:507-515. https:// doi.org/10.1038/nrcardio.2014.83

7. Boudina S, Sena S, O'Neill BT, Tathireddy P, Young ME, Abel ED (2005) Reduced mitochondrial oxidative capacity and 
increased mitochondrial uncoupling impair myocardial energetics in obesity. Circulation 112:2686-2695. https://doi.org/10.1161/ CIRCULATIONAHA.105.554360

8. Camici PG, Crea F (2007) Coronary microvascular dysfunction. N Engl J Med 356:830-840. https://doi.org/10.1056/NEJMra0618 89

9. Carlsson M, Wilson M, Martin AJ, Saeed M (2009) Myocardial microinfarction after coronary microembolization in swine: MR imaging characterization. Radiology 250:703-713. https://doi. org/10.1148/radiol.2503081000

10. Chen C, Wei J, AlBadri A, Zarrini P, Bairey Merz CN (2016) Coronary microvascular dysfunction- epidemiology, pathogenesis, prognosis, diagnosis, risk factors and therapy. Circ J 81:3-11. https://doi.org/10.1253/circj.CJ-16-1002

11. Chong CR, Clarke K, Levelt E (2017) Metabolic remodeling in diabetic cardiomyopathy. Cardiovasc Res 113:422-430. https:// doi.org/10.1093/cvr/cvx018

12. Crea F, Bairey Merz CN, Beltrame JF, Kaski JC, Ogawa H, Ong P, Sechtem U, Shimokawa H, Camici PG, Coronary Vasomotion Disorders International Study G (2017) The parallel tales of microvascular angina and heart failure with preserved ejection fraction: a paradigm shift. Eur. Heart J. 38:473-477. https://doi. org/10.1093/eurheartj/ehw461

13. Crea F, Camici PG, Bairey Merz CN (2014) Coronary microvascular dysfunction: an update. Eur Heart J 35:1101-1111. https ://doi.org/10.1093/eurheartj/eht513

14. De Maria GL, Cuculi F, Patel N, Dawkins S, Fahrni G, Kassimis G, Choudhury RP, Forfar JC, Prendergast BD, Channon KM, Kharbanda RK, Banning AP (2015) How does coronary stent implantation impact on the status of the microcirculation during primary percutaneous coronary intervention in patients with ST-elevation myocardial infarction? Eur Heart J 36:3165-3177. https://doi.org/10.1093/eurheartj/ehv353

15. De Wijs-Meijler DP, Stam K, van Duin RW, Verzijl A, Reiss IK, Duncker DJ, Merkus D (2016) Surgical placement of catheters for long-term cardiovascular exercise testing in swine. J Vis Exp. https://doi.org/10.3791/53772

16. Dryer K, Gajjar M, Narang N, Lee M, Paul J, Shah AP, Nathan S, Butler J, Davidson CJ, Fearon WF, Shah SJ, Blair JEA (2018) Coronary microvascular dysfunction in patients with heart failure with preserved ejection fraction. Am J Physiol Heart Circ Physiol 314:H1033-H1042. https://doi.org/10.1152/ajphe art.00680.2017

17. Duncker DJ, Bache RJ (2008) Regulation of coronary blood flow during exercise. Physiol Rev 88:1009-1086. https://doi. org/10.1152/physrev.00045.2006

18. Duncker DJ, Koller A, Merkus D, Canty JM Jr (2015) Regulation of coronary blood flow in health and ischemic heart disease. Prog Cardiovasc Dis 57:409-422. https://doi.org/10.1016/j. pcad.2014.12.002

19. Frangogiannis NG (2015) Pathophysiology of myocardial infarction. Compr Physiol 5:1841-1875. https://doi.org/10.1002/cphy. c150006

20. Franssen C, Chen S, Unger A, Korkmaz HI, De Keulenaer GW, Tschope C, Leite-Moreira AF, Musters R, Niessen HW, Linke WA, Paulus WJ, Hamdani N (2016) Myocardial microvascular inflammatory endothelial activation in heart failure with preserved ejection fraction. JACC Heart Fail 4:312-324. https:// doi.org/10.1016/j.jchf.2015.10.007

21. Goyal SN, Reddy NM, Patil KR, Nakhate KT, Ojha S, Patil CR, Agrawal YO (2016) Challenges and issues with streptozotocin-induced diabetes - a clinically relevant animal model to understand the diabetes pathogenesis and evaluate therapeutics. Chem Biol Interact 244:49-63. https://doi.org/10.1016/j. cbi.2015.11.032
22. Gray LR, Tompkins SC, Taylor EB (2014) Regulation of pyruvate metabolism and human disease. Cell Mol Life Sci 71:2577-2604. https://doi.org/10.1007/s00018-013-1539-2

23. Guarini G, Kiyooka T, Ohanyan V, Pung YF, Marzilli M, Chen YR, Chen CL, Kang PT, Hardwick JP, Kolz CL, Yin L, Wilson GL, Shokolenko I, Dobson JG Jr, Fenton R, Chilian WM (2016) Impaired coronary metabolic dilation in the metabolic syndrome is linked to mitochondrial dysfunction and mitochondrial DNA damage. Basic Res Cardiol 111:29. https://doi.org/10.1007/s0039 5-016-0547-4

24. Gupta A, Taqueti VR, van de Hoef TP, Bajaj NS, Bravo PE, Murthy VL, Osborne MT, Seidelmann SB, Vita T, Bibbo CF, Harrington $\mathrm{M}$, Hainer J, Rimoldi O, Dorbala S, Bhatt DL, Blankstein R, Camici PG, Di Carli MF (2017) Integrated noninvasive physiological assessment of coronary circulatory function and impact on cardiovascular mortality in patients with stable coronary artery disease. Circulation 136:2325-2336. https://doi.org/10.1161/ CIRCULATIONAHA.117.029992

25. Haas AV, Rosner BA, Kwong RY, Rao AD, Garg R, Di Carli MF, Adler GK (2019) Sex differences in coronary microvascular function in individuals with type 2 diabetes. Diabetes 68:631-636. https://doi.org/10.2337/db18-0650

26. Heather LC, Clarke K (2011) Metabolism, hypoxia and the diabetic heart. J Mol Cell Cardiol 50:598-605. https://doi. org/10.1016/j.yjmcc.2011.01.007

27. Herrmann J, Haude M, Lerman A, Schulz R, Volbracht L, Ge J, Schmermund A, Wieneke H, von Birgelen C, Eggebrecht H, Baumgart D, Heusch G, Erbel R (2001) Abnormal coronary flow velocity reserve after coronary intervention is associated with cardiac marker elevation. Circulation 103:2339-2345. https:// doi.org/10.1161/01.cir.103.19.2339

28. Heusch G (2019) Myocardial ischemia: lack of coronary blood flow, myocardial oxygen supply-demand imbalance, or what? Am J Physiol Heart Circ Physiol 316:H1439-H1446. https://doi. org/10.1152/ajpheart.00139.2019

29. Heusch G, Skyschally A, Kleinbongard P (2018) Coronary microembolization and microvascular dysfunction. Int J Cardiol 258:17-23. https://doi.org/10.1016/j.ijcard.2018.02.010

30. Hubbard L, Lipinski J, Ziemer B, Malkasian S, Sadeghi B, Javan H, Groves EM, Dertli B, Molloi S (2018) Comprehensive assessment of coronary artery disease by using first-pass analysis dynamic CT perfusion: validation in a swine model. Radiology 286:93-102. https://doi.org/10.1148/radiol.2017162821

31. Imamura $S$, Hirata $\mathrm{K}$, Orii $\mathrm{M}$, Shimamura $\mathrm{K}$, Shiono $\mathrm{Y}$, Ishibashi K, Tanimoto T, Yamano T, Ino Y, Kitabata H, Yamaguchi T, Kubo T, Tanaka A, Imanishi T, Akasaka T (2014) Relation of albuminuria to coronary microvascular function in patients with chronic kidney disease. Am J Cardiol 113:779-785. https://doi. org/10.1016/j.amjcard.2013.11.026

32. Jespersen L, Hvelplund A, Abildstrom SZ, Pedersen F, Galatius S, Madsen JK, Jorgensen E, Kelbaek H, Prescott E (2012) Stable angina pectoris with no obstructive coronary artery disease is associated with increased risks of major adverse cardiovascular events. Eur Heart J 33:734-744. https://doi.org/10.1093/eurheartj/ ehr331

33. Keytsman C, Dendale P, Hansen D (2015) Chronotropic incompetence during exercise in type 2 diabetes: aetiology, assessment methodology, prognostic impact and therapy. Sports Med. 45:985-995. https://doi.org/10.1007/s40279-015-0328-5

34. Klein DA, Katz DH, Beussink-Nelson L, Sanchez CL, Strzelczyk TA, Shah SJ (2015) Association of chronic kidney disease with chronotropic incompetence in heart failure with preserved ejection fraction. Am J Cardiol 116:1093-1100. https://doi.org/10.1016/j. amjcard.2015.06.038

35. Lerman LO, Kurtz TW, Touyz RM, Ellison DH, Chade AR, Crowley SD, Mattson DL, Mullins JJ, Osborn J, Eirin A, Reckelhoff JF, 
Iadecola C, Coffman TM (2019) Animal models of hypertension: a scientific statement from the American Heart Association. Hypertension 73:e87-e120. https://doi.org/10.1161/HYP.00000 00000000090

36. Levy BI, Heusch G, Camici PG (2019) The many faces of myocardial ischaemia and angina. Cardiovasc Res 115:1460-1470. https://doi.org/10.1093/cvr/cvz160

37. Lindsey ML, Bolli R, Canty JM Jr, Du XJ, Frangogiannis NG, Frantz S, Gourdie RG, Holmes JW, Jones SP, Kloner RA, Lefer DJ, Liao R, Murphy E, Ping P, Przyklenk K, Recchia FA, Schwartz Longacre L, Ripplinger CM, Van Eyk JE, Heusch G (2018) Guidelines for experimental models of myocardial ischemia and infarction. Am J Physiol Heart Circ Physiol 314:H812-H838. https://doi.org/10.1152/ajpheart.00335.2017

38. Liu A, Wijesurendra RS, Liu JM, Forfar JC, Channon KM, Jerosch-Herold M, Piechnik SK, Neubauer S, Kharbanda RK, Ferreira VM (2018) Diagnosis of microvascular angina using cardiac magnetic resonance. J Am Coll Cardiol 71:969-979. https://doi. org/10.1016/j.jacc.2017.12.046

39. Mohammed SF, Hussain S, Mirzoyev SA, Edwards WD, Maleszewski JJ, Redfield MM (2015) Coronary microvascular rarefaction and myocardial fibrosis in heart failure with preserved ejection fraction. Circulation 131:550-559. https://doi.org/10.1161/ CIRCULATIONAHA.114.009625

40. Niccoli G, Scalone G, Crea F (2015) Acute myocardial infarction with no obstructive coronary atherosclerosis: mechanisms and management. Eur Heart J 36:475-481. https://doi.org/10.1093/ eurheartj/ehu469

41. Obokata M, Reddy YNV, Melenovsky V, Kane GC, Olson TP, Jarolim P, Borlaug BA (2018) Myocardial injury and cardiac reserve in patients with heart failure and preserved ejection fraction. J Am Coll Cardiol 72:29-40. https://doi.org/10.1016/j. jacc.2018.04.039

42. Ong P, Athanasiadis A, Borgulya G, Vokshi I, Bastiaenen R, Kubik S, Hill S, Schaufele T, Mahrholdt H, Kaski JC, Sechtem U (2014) Clinical usefulness, angiographic characteristics, and safety evaluation of intracoronary acetylcholine provocation testing among 921 consecutive white patients with unobstructed coronary arteries. Circulation 129:1723-1730. https://doi.org/10.1161/ CIRCULATIONAHA.113.004096

43. Ostergaard L, Kristiansen SB, Angleys H, Frokiaer J, Michael Hasenkam J, Jespersen SN, Botker HE (2014) The role of capillary transit time heterogeneity in myocardial oxygenation and ischemic heart disease. Basic Res Cardiol 109:409. https://doi. org/10.1007/s00395-014-0409-x

44. Pacheco Claudio C, Quesada O, Pepine CJ, Bairey Merz NC (2018) Why names matter for women: mINOCA/INOCA (myocardial infarction/ischemia and no obstructive coronary artery disease). Clin Cardiol 41:185-193. https://doi.org/10.1002/clc.22894

45. Paulus WJ, Tschope C (2013) A novel paradigm for heart failure with preserved ejection fraction comorbidities drive myocardial dysfunction and remodeling through coronary microvascular endothelial inflammation. J Am Coll Cardiol 62:263-271. https ://doi.org/10.1016/J.Jacc.2013.02.092

46. Picchi A, Limbruno U, Focardi M, Cortese B, Micheli A, Boschi L, Severi S, De Caterina R (2011) Increased basal coronary blood flow as a cause of reduced coronary flow reserve in diabetic patients. Am J Physiol Heart Circ Physiol 301:H2279-2284. https://doi.org/10.1152/ajpheart.00615.2011

47. Planer D, Mehran R, Ohman EM, White HD, Newman JD, Xu K, Stone GW (2014) Prognosis of patients with non-ST-segment-elevation myocardial infarction and nonobstructive coronary artery disease: propensity-matched analysis from the Acute Catheterization and Urgent Intervention Triage Strategy trial. Circ Cardiovasc Interv 7:285-293. https://doi.org/10.1161/CIRCINTERVENTIO NS.113.000606
48. Radenkovic M, Stojanovic M, Prostran M (2016) Experimental diabetes induced by alloxan and streptozotocin: the current state of the art. J Pharmacol Toxicol Methods 78:13-31. https://doi. org/10.1016/j.vascn.2015.11.004

49. Radhakrishnan A, Pickup LC, Price AM, Law JP, Edwards NC, Steeds RP, Ferro CJ, Townend JN (2019) Coronary microvascular dysfunction: a key step in the development of uraemic cardiomyopathy? Heart 105:1302-1309. https://doi.org/10.1136/heart jnl-2019-315138

50. Rahman H, Ryan M, Lumley M, Modi B, McConkey H, Ellis H, Scannell C, Clapp B, Marber M, Webb A, Chiribiri A, Perera D (2019) Coronary microvascular dysfunction is associated with myocardial ischemia and abnormal coronary perfusion during exercise. Circulation 140:1805-1816. https://doi.org/10.1161/ CIRCULATIONAHA.119.041595

51. Sadeghi-Alavijeh O, Tadayyon M, Caplin B (2017) Chronic kidney disease-associated cardiovascular disease: scope and limitations of animal models. Cardiovasc Endocrinol 6:120-127. https ://doi.org/10.1097/XCE.0000000000000132

52. Shah MS, Brownlee M (2016) Molecular and cellular mechanisms of cardiovascular disorders in diabetes. Circ Res 118:1808-1829. https://doi.org/10.1161/CIRCRESAHA.116.306923

53. Sharaf B, Wood T, Shaw L, Johnson BD, Kelsey S, Anderson RD, Pepine CJ, Bairey Merz CN (2013) Adverse outcomes among women presenting with signs and symptoms of ischemia and no obstructive coronary artery disease: findings from the National Heart, Lung, and Blood Institute-sponsored Women's Ischemia Syndrome Evaluation (WISE) angiographic core laboratory. Am Heart J 166:134-141. https://doi.org/10.1016/j. ahj.2013.04.002

54. Sorop O, Heinonen I, van Kranenburg M, van de Wouw J, de Beer VJ, Nguyen ITN, Octavia Y, van Duin RWB, Stam K, van Geuns RJ, Wielopolski PA, Krestin GP, van den Meiracker AH, Verjans R, van Bilsen M, Danser AHJ, Paulus WJ, Cheng C, Linke WA, Joles JA, Verhaar MC, van der Velden J, Merkus D, Duncker DJ (2018) Multiple common comorbidities produce left ventricular diastolic dysfunction associated with coronary microvascular dysfunction, oxidative stress, and myocardial stiffening. Cardiovasc Res 114:954-964. https://doi.org/10.1093/cvr/cvy038

55. Sorop O, Merkus D, de Beer VJ, Houweling B, Pistea A, McFalls EO, Boomsma F, van Beusekom HM, van der Giessen WJ, VanBavel E, Duncker DJ (2008) Functional and structural adaptations of coronary microvessels distal to a chronic coronary artery stenosis. Circ Res 102:795-803. https://doi.org/10.1161/CIRCR ESAHA.108.172528

56. Sorop O, van de Wouw J, Chandler S, Ohanyan V, Tune JD, Chilian WM, Merkus D, Bender SB, Duncker DJ (2020) Experimental animal models of coronary microvascular dysfunction. Cardiovasc Res. https://doi.org/10.1093/cvr/cvaa002

57. Sorop O, van den Heuvel M, van Ditzhuijzen NS, de Beer VJ, Heinonen I, van Duin RW, Zhou Z, Koopmans SJ, Merkus D, van der Giessen WJ, Danser AH, Duncker DJ (2016) Coronary microvascular dysfunction after long-term diabetes and hypercholesterolemia. Am J Physiol Heart Circ Physiol 311:H1339-H1351. https://doi.org/10.1152/ajpheart.00458.2015

58. Srivaratharajah K, Coutinho T, deKemp R, Liu P, Haddad H, Stadnick E, Davies RA, Chih S, Dwivedi G, Guo A, Wells GA, Bernick J, Beanlands R, Mielniczuk LM (2016) Reduced myocardial flow in heart failure patients with preserved ejection fraction. Circ Heart Fail. https://doi.org/10.1161/CIRCHEARTFAILUR E.115.002562

59. Taqueti VR, Shaw LJ, Cook NR, Murthy VL, Shah NR, Foster CR, Hainer J, Blankstein R, Dorbala S, Di Carli MF (2017) Excess cardiovascular risk in women relative to men referred for coronary angiography is associated with severely impaired coronary flow 
reserve, not obstructive disease. Circulation 135:566-577. https ://doi.org/10.1161/CIRCULATIONAHA.116.023266

60. Taqueti VR, Solomon SD, Shah AM, Desai AS, Groarke JD, Osborne MT, Hainer J, Bibbo CF, Dorbala S, Blankstein R, Di Carli MF (2018) Coronary microvascular dysfunction and future risk of heart failure with preserved ejection fraction. Eur Heart $\mathbf{J}$ 39:840-849

61. Tonneijck L, Muskiet MH, Smits MM, van Bommel EJ, Heerspink HJ, van Raalte DH, Joles JA (2017) Glomerular hyperfiltration in diabetes: mechanisms, clinical significance, and treatment. J Am Soc Nephrol 28:1023-1039. https://doi.org/10.1681/ASN.20160 60666

62. van de Wouw J, Broekhuizen M, Sorop O, Joles JA, Verhaar MC, Duncker DJ, Danser AHJ, Merkus D (2019) Chronic kidney disease as a risk factor for heart failure with preserved ejection fraction: a focus on microcirculatory factors and therapeutic targets. Front Physiol 10:1108. https://doi.org/10.3389/fphys.2019.01108

63. van den Heuvel M, Sorop O, Koopmans SJ, Dekker R, de Vries R, van Beusekom HM, Eringa EC, Duncker DJ, Danser AH, van der Giessen WJ (2012) Coronary microvascular dysfunction in a porcine model of early atherosclerosis and diabetes. Am J Physiol Heart Circ Physiol 302:H85-H94. https://doi.org/10.1152/ ajpheart.00311.2011

64. van Essen GJ, Te Lintel Hekkert M, Sorop O, Heinonen I, van der Velden J, Merkus D, Duncker DJ (2018) Cardiovascular function of modern pigs does not comply with allometric scaling laws. Sci Rep 8:792. https://doi.org/10.1038/s41598-017-18775-z

65. Vitullo JC, Penn MS, Rakusan K, Wicker P (1993) Effects of hypertension and aging on coronary arteriolar density. Hypertension 21:406-414. https://doi.org/10.1161/01.hyp.21.4.406

66. Zorach B, Shaw PW, Bourque J, Kuruvilla S, Balfour PC Jr, Yang Y, Mathew R, Pan J, Gonzalez JA, Taylor AM, Meyer CH, Epstein FH, Kramer CM, Salerno M (2018) Quantitative cardiovascular magnetic resonance perfusion imaging identifies reduced flow reserve in microvascular coronary artery disease. J Cardiovasc Magn Reson 20:14. https://doi.org/10.1186/s12968-018-0435-1

\section{Affiliations}

\section{Jens van de Wouw ${ }^{1}$. Oana Sorop ${ }^{1} \cdot$ Ruben W. A. van Drie ${ }^{1} \cdot$ Richard W. B. van Duin ${ }^{1} \cdot$ Isabel T. N. Nguyen $^{2}$. Jaap A. Joles ${ }^{2}$. Marianne C. Verhaar ${ }^{2}$. Daphne Merkus ${ }^{1,3,4}$. Dirk J. Duncker ${ }^{1}$}

1 Division of Experimental Cardiology, Department of Cardiology, Thoraxcenter, Erasmus MC, University Medical Center Rotterdam, PO Box 2040, 3000 CA Rotterdam, The Netherlands

2 Department of Nephrology and Hypertension, University Medical Center Utrecht, Utrecht, The Netherlands
Walter Brendel Center of Experimental Medicine (WBex), LMU Munich, 81377 Munich, Germany

4 German Center for Cardiovascular Research (DZHK), Partner Site Munich, Munich Heart Alliance (MHA), 81377 Munich, Germany 